\title{
Technical Basis Document for At-Power Significance Determination Process (SDP) Notebooks
}

M. A. Azarm, P. K. Samanta, G. Martinez-Guridi, and J. Higgins

May 2004

Brookhaven National Laboratory

Upton, NY 11973-5000 


\section{DISCLAIMER}

This report was prepared as an account of work sponsored by an agency of the United States Government. Neither the United States Government nor any agency thereof, nor any of their employees, nor any of their contractors, subcontractors or their employees, makes any warranty, express or implied, or assumes any legal liability or responsibility for the accuracy, completeness, or any third party's use or the results of such use of any information, apparatus, product, or process disclosed, or represents that its use would not infringe privately owned rights. Reference herein to any specific commercial product, process, or service by trade name, trademark, manufacturer, or otherwise, does not necessary constitute or imply its endorsement, recommendation, or favoring by the United States Government or any agency thereof or its contractors or subcontractors. The views and opinions of authors expresses herein do not necessarily state to reflect those of the United States Government or any agency thereof. 


\title{
Technical Basis Document for At-Power Significance Determination Process (SDP) Notebooks
}

\author{
M. A. Azarm, P. K. Samanta, G. Martinez-Guridi, and J. Higgins \\ Energy Sciences and Technology Department \\ Brookhaven National Laboratory \\ Upton, NY 11973-5000 \\ www.bnl.gov \\ Managed by \\ Brookhaven Science Associates, LLC \\ for the United States Department of Energy under \\ Contract No. DE-AC02-98CH10886
}

May 2004

Prepared for

Division of Systems Safety and Analysis

Office of Nuclear Reactor Regulation

United States Nuclear Regulatory Commission 


\begin{abstract}
To support the assessment of inspection findings as part of the risk-informed inspection in the United States Nuclear Regulatory Commission's (USNRC's) Reactor Oversight Process (ROP), risk inspection notebooks, also called significance determination process (SDP) notebooks, have been developed for each of the operating plants in the United States. These notebooks serve as a tool for assessing risk significance of inspection findings along with providing an engineering understanding of the significance. Plant-specific notebooks are developed to capture plant-specific features, characteristics, and analyses that influence the risk profile of the plant. At the same time, the notebooks follow a consistent set of assumptions and guidelines to assure consistent treatment of inspection findings across the plants. To achieve these objectives, notebooks are designed to provide specific information that are unique both in the manner in which the information is provided and in the way the screening risk assessment is carried out using the information provided. The unique features of the SDP notebooks, the approaches used to present the information for assessment of inspection findings, the assumptions used in consistent modeling across different plants with due credit to plant-specific features and analyses form the technical basis of the SDP notebooks. In this document, the unique features and the technical basis for the notebooks are presented. The types of information that are included and the reasoning/basis for including that information are discussed. The rules and basis for developing the worksheets that are used by the inspectors in the assessment of inspection findings are presented. The approach to modeling plants' responses to different initiating events and specific assumptions/considerations used for each of the reactor types are also discussed.
\end{abstract}




\section{TABLE OF CONTENTS}

ABSTRACT

iii

LIST OF TABLES

vii

ACKNOWLEDGEMENTS

viii

LIST OF ACRONYMS

ix.

1. INTRODUCTION

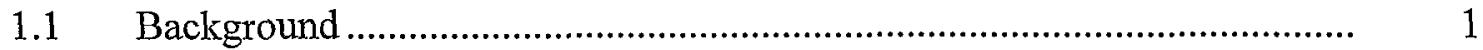

1.2 Use of the Document ................................................................................ 2

$1.3 \quad$ Organization of the Document..................................................................... 2

2. FEATURES OF THE TECHNICAL BASIS DOCUMENT …….........................

3. USE OF THE SDP NOTEBOOKS FOR ASSESSING INSPECTION FINDINGS 6

3.1 Input Information for Using the Notebooks..................................................

3.2 Use of the Notebook in Assessing the Significance of Inspection Findings.

3.3 Output of Results Using the Notebook

3.4 Example Risk Significance Assessment and Comparison with Plant-Specific Results

3.5 Basis for the Approach Used

4. UNIQUE FEATURES OF SDP NOTEBOOKS.

5. BASIS FOR SELECTION AND CATEGORIES OF INITIATING EVENTS......

6. SYSTEMS/COMPONENTS AND DEPENDENCY INFORMATION ................. 20

6.1 Systems/Components Information to Support Inspection Assessment....... 20

6.2 Use of Dependency Information

6.3 Defining Applicable Initiating Events for Assessment of Inspection Findings.

7. GENERAL RULES AND BASIS FOR DEVELOPING THE WORKSHEETS USED FOR ASSESSMENT OF INSPECTION FINDINGS

8. BASIS FOR MODELING RESPONSES TO INITIATING EVENTS ................... 27

8.1 Safety Functions..................................................................................... 27

8.2 Creditable Mitigation Capability ............................................................... 27

8.3 Creditable Mitigation Capability: Hardware vs Operator Failure................ 28 


\section{TABLE OF CONTENTS (Continued)}

Page

8.4 Hardware Failures: Consideration of Common-cause Failures and Dependency on Support Systems $\ldots \ldots \ldots \ldots \ldots \ldots \ldots \ldots .28$

8.5 Operator Action Credit $\ldots \ldots \ldots \ldots \ldots \ldots \ldots \ldots \ldots \ldots \ldots . .29$

9. MODELING RESPONSE TO INITIATING EVENTS FOR EACH REACTOR TYPE $\ldots \ldots \ldots \ldots \ldots \ldots \ldots \ldots \ldots \ldots \ldots \ldots \ldots \ldots \ldots \ldots \ldots \ldots \ldots \ldots \ldots \ldots, 32$

9.1 Pressurized Water Reactors: Babcock and Wilcox (B\&W) Plants ..... 32

9.2 Pressurized Water Reactors: Combustion Engineering (CE) Plants .... 38

9.3 Pressurized Water Reactors: Westinghouse (W) Plants .......... 44

9.4 Boiling Water Reactors: General Electric (GE) Plants .......... 52

10. APPLICABILITY OF THE SDP NOTEBOOKS $\ldots \ldots \ldots \ldots \ldots \ldots \ldots . \ldots 6$

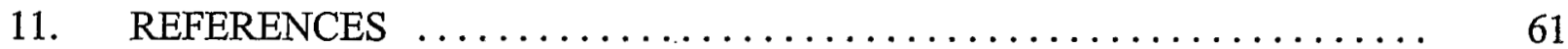

APPENDIX A USAGE RULES FOR SIGNIFICANCE DETERMINATION OF REACTOR INSPECTION FINDINGS FOR AT-POWER

SITUATIONS $\ldots \ldots \ldots \ldots \ldots \ldots \ldots \ldots \ldots \ldots \ldots \ldots \ldots \ldots$ A-1

APPENDIX B $\quad$ OPERATOR ACTION CREDIT FOR SDP NOTEBOOKS . . . . . . B B-1 


\section{LIST OF TABLES}

Table

1a Categories of Initiating Events for a PWR Plant $\ldots \ldots \ldots \ldots \ldots \ldots$

1b Categories of Initiating Events for a BWR Plant $\ldots \ldots \ldots \ldots \ldots \ldots$

$2 \quad$ Remaining Capability Rating Value $\ldots \ldots \ldots \ldots \ldots \ldots \ldots \ldots \ldots \ldots$ 


\section{ACKNOWLEDGEMENTS}

This report has benefitted from the technical input that was provided by various NRC/NRR staff and the Regional Senior Risk Analysts. The authors would like to thank specifically Mr. P. Wilson, Mr. M. Franovich, and Mr. R. Perch of the NRC/NRR for their review and comment. We also would like to thank Ms. J. Frejka of BNL for her diligent secretarial support on this project and Ms. C. Conrad of BNL for her expert technical review. 


\section{LIST OF ACRONYMS}

$\begin{array}{ll}\text { ACC } & \text { Accumulator } \\ \text { ADS } & \text { Automatic Depressurization System } \\ \text { ADV } & \text { Atmospheric Dump Valve } \\ \text { AFW } & \text { Auxiliary Feedwater } \\ \text { AMSAC } & \text { ATWS Mitigation System Actuation Circuitry } \\ \text { AOT } & \text { Allowed Outage Time } \\ \text { ARI } & \text { Automatic Rod Insertion } \\ \text { ASD } & \text { Automatic Steam-driven } \\ \text { ATWS } & \text { Anticipated Transients Without Scram } \\ \text { B\&W } & \text { Babcock and Wilcox } \\ \text { BJ } & \text { Byron-Jackson } \\ \text { BWR } & \text { Boiling Water Reactor } \\ \text { BWST } & \text { Borated Water Storage Tank } \\ \text { CCW } & \text { Component Cooling Water } \\ \text { CDF } & \text { Core Damage Frequency } \\ \text { CE } & \text { Combustion Engineering } \\ \text { CFT } & \text { Core Flood Tank } \\ \text { CHR } & \text { Containment Heat Removal } \\ \text { CRD } & \text { Control Rod Drive } \\ \text { CST } & \text { Condensate Storage Tank } \\ \text { CV } & \text { Containment Venting } \\ \text { ECCS } & \text { Emergency Core Cooling System } \\ \text { EDG } & \text { Emergency Diesel Generator } \\ \text { EFW } & \text { Emergency Feedwater } \\ \text { ERV } & \text { Electromatic Relief Valve } \\ \text { ESW } & \text { Emergency Service Water } \\ \text { HEP } & \text { Human Error Probability } \\ \text { HPCI } & \text { High Pressure Coolant Injection } \\ \text { HPCS } & \text { High Pressure Core Spray } \\ \text { HPI } & \text { High Pressure Injection } \\ \text { HPR } & \text { High Pressure Recirculation } \\ \text { HPSI } & \text { High Pressure Safety Injection } \\ \text { HPSW } & \text { High Pressure Service Water } \\ \text { HVAC } & \text { Heating, Ventilation, and Air Conditioning } \\ \text { ICW } & \text { Intermediate Cooling Water } \\ \text { IEF } & \text { Initiating Event Frequency } \\ \text { IEL } & \text { Initiating Event Likelihood } \\ \text { IPE } & \text { Individual Plant Examination } \\ \text { ISLOCA } & \text { Interfacing System LOCA } \\ \text { LCCW } & \text { Loss of Component Cooling Water } \\ \text { LEAC } & \text { LOOP with Loss of an Emergency AC Bus } \\ \text { LERF } & \text { Large Early Release Frequency } \\ \text { LI } & \text { Late Injection } \\ & \end{array}$




\section{LIST OF ACRONYMS}

(Continued)

$\begin{array}{ll}\text { LLOCA } & \text { Large LOCA } \\ \text { LOCA } & \text { Loss of Coolant Accident } \\ \text { LOIA } & \text { Loss of Instrument Air } \\ \text { LOOP } & \text { Loss of Offsite Power } \\ \text { LOSC } & \text { Loss of Seal Cooling } \\ \text { LOSW } & \text { Loss of Service Water } \\ \text { LPCI } & \text { Low Pressure Coolant Injection } \\ \text { LPCS } & \text { Low Pressure Core Spray } \\ \text { LPI } & \text { Low Pressure Injection } \\ \text { LPR } & \text { Low Pressure Recirculation } \\ \text { LPSI } & \text { Low Pressure Safety Injection } \\ \text { MFW } & \text { Main Feedwater } \\ \text { MLOCA } & \text { Medium LOCA } \\ \text { MSIV } & \text { Main Steam Isolation Valve } \\ \text { MSLB } & \text { Main Steam Line Break } \\ \text { MSSV } & \text { Main Steam Safety Valve } \\ \text { NPSH } & \text { Normal Pump Suction Head } \\ \text { NRC } & \text { Nuclear Regulatory Commission } \\ \text { NSCCC } & \text { Nuclear Service Closed Cycle Cooling } \\ \text { PCS } & \text { Power Conversion System } \\ \text { PORV } & \text { Power-operated Relief Valve } \\ \text { PRA } & \text { Probabilistic Risk Assessment } \\ \text { PSV } & \text { Pressurizer Safety Valve } \\ \text { PTS } & \text { Pressurized Thermal Shock } \\ \text { PWR } & \text { Pressurized Water Reactor } \\ \text { RAS } & \text { Recirculation Actuation Signal } \\ \text { RAW } & \text { Risk Achievement Worth } \\ \text { RCIC } & \text { Reactor Core Isolation Cooling } \\ \text { RCP } & \text { Reactor Coolant Pump } \\ \text { RCS } & \text { Reactor Coolant System } \\ \text { RCSDEP } & \text { Reactor Coolant System Depressurization } \\ \text { RHR } & \text { Residual Heat Removal } \\ \text { RHRSW } & \text { Residual Heat Removal Service Water } \\ \text { ROP } & \text { Reactor Oversight Process } \\ \text { RWST } & \text { Refueling Water Storage Tank } \\ \text { RWT } & \text { Refueling Water Tank } \\ \text { SBO } & \text { Station Blackout } \\ \text { SDC } & \text { Shutdown Cooling } \\ \text { SDP } & \text { Significance Determination Process } \\ \text { SG } & \text { Steam Generator } \\ \text { SGTR } & \text { Steam Generator Tube Rupture } \\ \text { SHR } & \text { Secondary Heat Removal } \\ & \end{array}$




\section{LIST OF ACRONYMS \\ (Continued)}

$\begin{array}{ll}\text { SI } & \text { Safety Injection } \\ \text { SIT } & \text { Safety Injection Tank } \\ \text { SLC } & \text { Standby Liquid Control } \\ \text { SLOCA } & \text { Small LOCA } \\ \text { SORV } & \text { Stuck-Open Relief Valve or Stuck-Open PORV } \\ \text { SPC } & \text { Suppression Pool Cooling } \\ \text { SRA } & \text { Senior Reactor Analyst } \\ \text { SRV } & \text { Safety Relief Valve } \\ \text { SW } & \text { Service Water } \\ \text { TBV } & \text { Turbine Bypass Valve } \\ \text { W } & \text { Westinghouse }\end{array}$




\section{INTRODUCTION}

\subsection{Background}

The United States Nuclear Regulatory Commission's (USNRC's) new Reactor Oversight Process (ROP) includes a Significance Determination Process (SDP) methodology for risk characterization of inspection findings. The SDP methodology for risk characterization involves three phases in arriving at a risk significance of an inspection finding assuring that risk-significant findings are identified and that findings with minimal implications for risk are screened out. The Phase 2 of the SDP requires inspectors to obtain a risk-significance approximation and basis for the inspection findings. To aid the inspectors in conducting the SDP Phase 2 assessment, plant-specific risk inspection notebooks, also called the SDP notebooks, have been developed.

The Rev. 0 version of the SDP notebook for each of the operating plants was initially developed from the available Individual Plant Examination (IPE) submittal. To assure that the notebooks adequately captured the risk insights, a benchmarking of the notebooks was carried out comparing their results with that from the plant-specific probabilistic risk assessments (PRAs). As part of the benchmarking, updated plant-specific information and data were also obtained. This updated plantspecific information along with the insights from benchmarking were used to develop the Rev. 1 versions of the notebook.

The SDP notebooks used information from the plant-specific PRAs, plant system notebooks, and other relevant documentation to define a tool for inspectors that can provide a quick screening assessment of the risk significance of an inspection finding, along with an engineering understanding of the significance of the finding. The SDP notebooks are unique both in the manner in which they provide the information and in the way the screening assessment is carried out using the information provided.

Plant-specific SDP notebooks were developed to capture plant-specific features, characteristics, and analyses that influence the risk profile of the plant. At the same time, plants of similar vendor design have many similar features and common characteristics. In some cases, approaches to modeling in the PRAs were different which implied different risk significance for similar findings at different plants of similar design. For the Phase 2 assessment using the SDP notebooks, a consistent approach was used where similar aspects of plants were treated similarly with due credit to plant-specific features and analyses. The development of the SDP notebook followed a consistent set of assumptions and guidelines to assure consistent treatment of inspection findings across the plants. This set of assumptions and guidelines, used in developing the SDP notebooks, were, however, modified or refined, as needed, based on the lessons learned from benchmarking and comparing different plants. Modifications of assumptions and guidelines provided credit for specific features and analyses, and removed unnecessary conservatism in the Phase 2 SDP assessment.

SDP notebooks were developed to provide specific information to the inspectors and to serve as a tool for assessing risk significance of inspection findings considering the specific needs of the Phase 2 SDP assessment. The unique features of the SDP notebooks, the approaches used to present the information for screening assessment of inspection findings, and the assumptions used in consistent modeling across different plants with due credit to plant-specific features and analyses 
formed the technical basis of the SDP notebooks. In this document, the unique features and the technical basis for the notebooks are presented.

This technical basis for the notebooks essentially summarizes the assumptions and guidelines used for developing the notebooks; sometimes these assumptions and guidelines are referred to as "construction rules". These assumptions and guidelines, as presented here, are implemented in Rev. 2 or Standardized version of the notebooks. In earlier versions of the notebooks, differences exist since lessons learned during the preparations of the notebooks were used to refine the assumptions and guidelines. The revised assumptions and guidelines were used to develop the remaining notebooks and not others completed earlier. Following the completion of the Rev. 1 version of the notebooks, a review of the lessons learned was undertaken and assumptions and guidelines were further standardized. Rev. 2 or standardized versions of the notebooks are prepared considering these assumptions and guidelines or "construction rules" and updated plant-specific information including updated plant-specific PRA.

\subsection{Use of the Document}

The technical basis document for the SDP notebooks aids in multiple activities.

The document is primarily useful for the inspectors or users to understand the SDP notebooks, how the risk assessment of an inspection finding is carried out using the notebook, the assumptions involved in carrying out the assessment, and the limitations of the tool. Understanding these aspects help inspectors to better characterize the risk significance and basis of the inspection findings in the Phase 2 assessment.

The document also helps the Senior Reactor Analyst (SRA) or Risk Analyst in Phase 3 assessments clarifying the modeling assumptions and approximations made in the Phase 2 assessment using the notebook. Understanding the technical basis of the notebook helps in presenting an engineering understanding of the inspection finding and in comparing the risk significance with the licensee's analysis using the plant-specific PRAs. In many cases, it clearly brings in focus the assumptions made by the licensee in its model in assessing the risk significance of the finding which otherwise can be difficult to delineate. Given the Phase 2 assessment using the notebook, Phase 3 assessment can be conducted quickly focusing on the assumptions or modeling aspects that may be unnecessarily conservative for the plant-specific application or the specific inspection finding.

The technical basis document is useful to further standardize the treatment of inspection findings across the plants with due credit to plant-specific features and analyses. Assumptions and modeling of plant response to different initiators is made consistent considering similar design features bringing consistency in assessment of inspection findings across the plants. This approach of standardizing and assuring consistency reduces variability due to PRA modeling assumptions and quality issues.

\subsection{Organization of the Document}

The report is organized as follows: 
Chapter 2 defines the features of the technical basis document identifying the aspects addressed in this document and the types of information not included here. Chapter 3 gives an overview of how the SDP notebook is used to assess inspection findings and the basis for the overall approach. Chapter 4 discusses the unique features of the notebook considering the way the information is provided and the evaluation is conducted. Chapter 5 discusses the selection and categorization of the initiating events used in the notebook and their use in the evaluation process. Chapter 6 presents plant-specific system and component information included in the notebook along with dependency information and the initiating events to be evaluated for an inspection finding in a system. Chapter 7 presents the rules and basis for developing the worksheets. Chapter 8 discusses the basis for modeling the responses to the initiating events. It discusses the safety function, the approach to defining the mitigation capability for safety functions, and the approaches for assigning credits for hardware and operator failure considering the equipment reliability, common-cause failure, and human error probability considerations. Chapter 9 provides a discussion of the considerations in modeling the response to different initiators for each of the reactor types. Chapter 10 presents the limitations and applicability of the SDP notebooks. Two appendices are included. Appendix A provides a brief guidance on using the three-phase SDP process and the Usage Rules for assessing risk significance of inspection findings using the SDP notebooks. Appendix B provides the operator action credits for operator actions common across a type of plant based on survey of human error probability of such actions from the plant PRAs. 


\section{FEATURES OF THE TECHNICAL BASIS DOCUMENT}

The SDP notebook is a tool for the inspectors of nuclear power plants for use in assessing significance of inspection findings. To make the process simple, the information to be used by the inspector in obtaining the engineering understanding and the risk significance is presented in terms of tables in the notebook. Through the use of the tables, the inspectors can quickly obtain a screening assessment of the inspection finding. A significant portion of the basis underlying the approach used in the notebook is similar to the PRA of nuclear power plants. However, the inspectors do not require a detailed understanding of the PRA modeling nor of PRA jargon. In this document, the basis and the approach used for different aspects of the SDP notebook are presented to provide an inspector with an understanding of the assumptions and considerations involved in obtaining the assessment. This document addresses the following aspects:

1. It discusses different aspects of the notebook and how they are used to obtain an assessment of the significance of the inspection findings. In that regard, it provides the top-level basis of the notebook and the basis for the assessment of the inspection findings.

2. It discusses each part or table in the notebook and the basis for developing the information in the table. Each part or table in the notebook relate to one aspect or portion of the assessment of the inspection finding. The assumptions relating to that aspect of the notebook are identified.

3. Each notebook includes a set of tables defining plant response to different initiating events. Assumptions and considerations in modeling the plant response considering the plantspecific features and analyses are discussed here.

4. Plants from a particular reactor vendor type have many commonalities even though there may be differences in some system designs. The common characteristics are considered to treat them similarly in the notebooks. Each reactor type is discussed separately including a discussion for each of the initiating events. The reader can focus on the applicable reactor type without the need to refer to other reactor types, as needed, for understanding plant response to initiating events.

5. The approach to considering the availability of mitigation equipment, common cause failures, and treatment of human error is consistent across the plants and is unique to the SDP notebooks. These general aspects are discussed separately.

6. The use of the notebook to assess and screen significance of inspection findings is aided by Usage Rules and a computer spreadsheet. The use of the notebooks and the information obtained using the notebooks are also discussed here.

This document, however, does not address the following aspects:

1. It is not intended to describe the details of plant systems, procedures, and plant response to different initiators, but rather to describe the basis for the modeling for assessing risk significance of inspection findings. The reader is assumed to have knowledge of plant 
systems, plant response to initiators, emergency operating procedures, and treatment of initiators in PRA models.

2. This document discusses the modeling approach and assumptions used in developing the SDP notebooks. As discussed earlier, the intent of the notebooks is to obtain screening assessment of the inspection findings where plants of similar design are treated consistently with due credit to plant-specific features and analyses. The objective is not to identify any inadequacy or deficiency in plant-specific PRA modeling, but rather to present the approach to modeling plant-specific features and analyses used for SDP notebooks, and at the same time, identify any conservatism in SDP modeling for the screening phase in the significance determination process.

3. The modeling assumptions and success criteria used are not based on any separate, independent plant-specific evaluation, but rather using plant-specific information available in the plant PRAs. In some cases where the plant-specific information was either not available or not well supported, considering plants of similar design and using engineering judgment, some assumptions were made for screening evaluations in the SDP notebooks. The development of the notebook did not involve detailed evaluation of the plant-specific analyses that may have been conducted. 


\section{USE OF THE SDP NOTEBOOKS FOR ASSESSING INSPECTION FINDINGS}

The information provided in the SDP notebooks is used by the inspectors to assess the significance of inspection findings and to obtain an engineering understanding of the significance. Inspectors or users follow the information provided in a specific manner to achieve these objectives. Here, the manner in which the notebook is used to obtain the desired results or outputs and the underlying technical basis for the manner in which the information is combined is summarized.

\subsection{Input Information for Using the Notebooks}

The input information desired by the notebook is as follows:

1. A clearly defined inspection finding which identifies the degraded equipment or components making them unavailable to carry out the desired safety function and the period for which the condition existed.

2. Additional plant-specific information may be desired to identify the impact of the inspection finding. Failure of a component identified by the inspection may result in failure of multiple other components because of the dependency of other components on the failed component identified in the inspection finding. Dependency information is provided in the notebook, but additional details may be necessary to clarify such dependency. System notebooks, system drawings, and detailed dependency information that may have been developed as part of the plant-specific PRA provide such information.

\subsection{Use of the Notebook in Assessing the Significance of Inspection Findings}

The significance of an inspection finding is assessed in terms of the increase in core damage probability and large early release frequency at the plant due to the degraded condition identified by the inspection finding including the period of existence. To assess the increase in core damage probability, the notebook identifies the initiating event likelihood and mitigation capability affected by the inspection finding, and assesses the corresponding accident sequences that contribute to core damage and are impacted by the inspection finding. Contributions of different accident sequences are combined to obtain the increase in core damage probability. To obtain a large early release frequency (LERF) contribution, the core damage contribution of accident sequences can be modified by a factor and combined to obtain an order of magnitude LERF contribution. The modifiers for LERF calculation is provided. The information provided in three tables in the notebook to support the assessment of significance of inspection findings is as follows.

1. Table 1 provides the initiating event likelihood (IEL) considering the initiating event frequency (IEF) and the exposure time of the degraded condition identified by the inspection finding. An inspection finding may impact either the likelihood of an initiating event or the mitigation capability or both. When the IEF is impacted, the change in the frequency is considered in obtaining the IEL. When the IEF is not impacted, but the mitigation capability of the initiating event is impacted, then the IEL is obtained considering the designation of the initiating event already defined in the table. When both IEF and mitigation capability are 
impacted, the IEL for applicable initiating events is considered taking into consideration the increase in the IEF, as applicable, and considering the already defined designation for those initiating events where only mitigation capability are impacted.

2. Table 2 helps identify the components/system trains affected by the inspection finding and define the initiating events to be considered in assessing the increase in core damage probability. Given the equipment identified in a degraded condition by the inspection finding, it/they can be related to the system/component identified in the table, and the initiating events to be evaluated can be directly obtained from the table. In addition, using the system dependency information provided in the table, other components impacted by the degraded/failed component can also be identified. As noted in the input information, in some cases, detailed plant-specific information may be used to obtain further clarification or refinement of the list of components impacted. The IELs for the initiating events to be considered are obtained using Table 1 , as discussed above.

3. Table 3 of the notebook includes multiple worksheets, one for each of the initiating events, identifying the accidents sequences leading to core damage. Accident sequences are defined in terms of the IELs and safety functions that mitigate the event. Each worksheet, corresponding to each initiating event, is associated with multiple accident sequences defining the scenarios that lead to core damage. Based on the inspection finding, the impacted safety functions are identified, i.e., those safety functions where components/trains have been identified to be in degraded/failed condition, and the change in the capability of the safety function, given the inspection finding, is used to assess the revised or increased contribution of the accident sequence to core damage probability. Accident sequences for each of the worksheets impacted by the inspection finding are assessed to obtain the increased contribution to core damage probability. The Usage Rules (Appendix A) are provided to guide the user in assessing the accident sequences which contribute to the increase in core damage probability. The sequences that can also contribute to LERF are also identified. A modifier or factor for LERF is given to identify that the sequence contributes to LERF and to facilitate the evaluation of LERF contribution.

4. In the notebook, accident sequences are assessed in terms of numbers, e.g., 5, 6, 7, which approximately represent core damage probabilities of the order $1 \mathrm{E}-5,1 \mathrm{E}-6$, and $1 \mathrm{E}-7$ respectively. As discussed in Section 3.3 below, in combining the accident sequences, an accident sequences of the order of $1 \mathrm{E}-5$ is estimated at $3.3 \mathrm{E}-5$ to take into consideration the variability in the parameters involved. Representation of the accident sequence contribution to core damage probability in terms of numbers makes it easy for the user to obtain an order of magnitude evaluation of the risk significance and the corresponding color of the inspection finding. The assessed accident sequences for an inspection finding are combined to obtain the increase in core damage probability for the inspection finding. This process of combining the accident sequences is commonly referred to as the "counting process" and is facilitated by a computer spreadsheet using the EXCEL program. The LERF contribution is also obtained using the LERF modifier provided in the table. The contributions of the impacted accident sequences are entered into the spreadsheet program which then provides the increase in core damage probability and in LERF. The color for the inspection finding based on both core damage probability and LERF is provided. 
5. Table 4 of the notebook provides a benchmarking of the risk significance of inspection findings for the plant using the notebook and comparing them to the risk significance obtained using the plant-specific PRA. Selected components and operator actions are evaluated and compared. Cases in which the risk significance evaluated by the notebook is under (non-conservative)- or over (conservative)-estimated compared to the plant-specific PRA are noted. Explanation is provided when the notebook results are non-conservative or overly conservative, i.e., an overestimate by two or more orders of magnitude. This table helps the user in directly obtaining an assessment of inspection findings for important components and operator actions, in assessment of other inspection findings, and in understanding the ability and usefulness of the tool in comparison to the plant-specific PRA.

\subsection{Output of Results Using the Notebook}

The color of the inspection finding as assessed provides the risk significance and the accident sequences that contribute to determining the color provide the engineering understanding of the assessed risk significance. In many cases, a number of accident sequences are affected, but usually, a small number of them dominate the contribution to the core damage probability. It is relatively easy to identify those accident sequences that dominate the contribution to core damage probability. These are the accident sequences whose values are small compared to other affected sequences (please note that a smaller value in our notation represents a higher probability, i.e., a 4 represents an increase in core damage probability of $1 \mathrm{E}-4$ whereas a 5 represents an increase in probability of 1E-5). Explaining these sequences in terms of the initiating event and the impact on the safety functions provides the engineering understanding needed to explain the risk significance of the inspection finding.

\subsection{Example Risk Significance Assessment and Comparison with Plant-Specific Results}

As mentioned in Section 3.2 above, Table 4 of the notebook, called the Benchmarking Table, presents a comparison of the risk significance of inspection findings using the notebook with that obtained using the plant-specific PRA. In this table, selected components representing different systems identified in Table 2 of the notebook and operator actions modeled in the worksheets (Table 3) are evaluated. To assure that the selection of components and operator actions in Table 4 for all notebooks is adequate and consistent across the plants, a guidance is used. This guidance is presented below.

For benchmarking, an inspection finding assumes the components or human actions to fail to perform the required function. For components, the period of the condition identified is one year which corresponds to $>30$ days for Expected Time for Degraded Condition under Initiating Event Likelihood in Table 1 of the notebook.

The selection of components and human actions for benchmarking follows a consistent approach for all the notebooks to provide the relevant information to the inspectors and facilitates use of the notebooks. It is recognized that benchmarking, a-priori all components and human actions of risk significance applicable for the plants, will be very resource consuming. It is also not needed since the notebook is the tool to carry out these evaluations. The intent in benchmarking is to adequately 
cover the components and human actions so that risk significant components in the systems are addressed and relevant differences between the notebook and the plant-specific PRA are understood.

The approach in selecting the components and human actions can be summarized as follows:

1. Table 2 of the notebook, Initiators and System Dependency Information, lists the systems and major components within the system modeled in the notebook. Inspection findings for these systems and components have the potential to be risk significant. Benchmarking is conducted at least for an inspection finding in each of the systems.

2. Multiple components in a system may be selected for benchmarking. Typically, a component within a system train is selected. For example, a RHR pump is selected to represent a train. Other components in the train are not selected when the significance of the findings for the components within the train are of the same color, i.e., within an order of magnitude. If there is a difference in significance, i.e., if the color of some component is noted to be higher based on the risk achievement worth (RAW) calculated by the plant PRA, then such a component may also be selected. For example, for the RHR system in a BWR, RHR heat exchanger is selected along with the RHR pump because the heat exchanger usually has a different color for the risk significance.

Systems with redundant trains may require selection of one component in each of the trains for benchmarking. However, if the colors of the inspection findings for the components in redundant trains are the same, i.e., their risk significance is of the same order of magnitude, then only one component may be selected to represent the inspection findings in multiple redundant trains. For example, the AFW system may consist of three trains with two trains with motor-driven pumps and one train with a turbine-driven pump. One of the motor-driven pumps may be selected to represent both the motor-driven trains when the RAW for both the motor-driven pumps are of the same order of magnitude. The turbine-driven pump is selected to represent the train with the turbine-driven pump. Usually, risk significance of the turbine-driven pump is of a different color. When the risk significance of the motor-driven pumps differ by one order of magnitude, i.e., color for one pump is different from the other, then both are selected.

3. For the $\mathrm{AC}$ power system, the $\mathrm{AC}$ buses and emergency diesel generators (EDGs) are considered. In some cases, because of the electrical loads associated with the AC buses, the RAW of different safety buses may be different by a color, and multiple buses may be chosen for benchmarking. When the RAW is of the same color, i.e., when the loading of the buses are similar, then one of the buses may be chosen. Similarly, if the EDGs have different colors for risk significance, then EDGs are separately benchmarked. In addition, if SBO DG or Gas turbine is used as the Alternate AC supply, then the associated equipment is chosen for benchmarking.

4. For the DC power system, DC buses, batteries, and battery chargers are considered. Again, similar to the discussions above, if the RAW values for different buses, batteries, or battery chargers are different to signify different colors, then each of the components is selected for 
benchmarking to assess the ability of the notebook to capture these differences. At least one DC bus, one battery, and one battery charger is chosen for benchmarking.

5. For support systems whose failures are special initiators, one of the major components is chosen for benchmarking. For example, for the instrument air system, one of the air compressors is usually chosen. If, however, any component in the system may result in complete loss of the system, then that component will also be chosen. In such cases, the component will also be associated with a high RAW.

6. The operator actions modeled in the notebook are considered for benchmarking. Some of the operator actions may not be modeled by the plant PRA and corresponding RAW values from the PRA may not be available. Also, in some cases, multiple operator actions in the PRA may be represented by a single action in the notebook, and a separate run considering the multiple operator actions may be needed to obtain a RAW for comparison.

\subsection{Basis for the Approach Used}

The notebook obtains an order of magnitude approximation to the risk significance of inspection finding using the process described above. In this process, the risk significance of an inspection finding is obtained in a manner similar to the methodology used in PRAs for a nuclear power plant. Similar to a PRA, different initiating events are considered and core damage scenarios are developed using event tree methodology. System modeling and plant-specific data evaluations are simplified for the order of magnitude evaluation. In this simplified approach, the mitigating capability of systems is defined in terms of redundant trains and their reliability is defined in terms of credits representing order of magnitude reliability.

In a PRA, the increase in a risk measure for a given condition, e.g., increase in core damage frequency for a failed component, is obtained by subtracting the basecase evaluation from the evaluation which includes the condition. In this process, accident sequences or cutsets which do not involve the condition being evaluated are eliminated and the delta increase of the affected sequences are combined to obtain the increase in the risk measure. Similarly, in the evaluation using the notebook, the accident sequences impacted by the inspection finding are evaluated which essentially provides the increase in risk or increase in core damage probability. For each accident sequence in the notebook evaluation, the measure is obtained in terms of probability since the time is embedded in the IEL. The IEL is obtained as a product of the initiating event frequency and the duration of the degraded condition giving a probability measure. Each of the accident sequences is evaluated considering an order of magnitude change in either the mitigation capability or the IEL and, thus, the new value obtained for the sequence is its contribution to the increase in core damage probability. For example, an accident sequence with a basecase value of 6 , representing $1 \mathrm{E}-6$, can be assessed to be 5 , representing $1 \mathrm{E}-5$, or 4 , representing $1 \mathrm{E}-4$. The new value 5 or 4 is essentially the increase in sequence contribution to the core damage probability since ([1E-5] - [1E-6]) is approximately $1 \mathrm{E}-5$, a 5 , or ([1E-4] - [1E-6]) is approximately equal to $1 \mathrm{E}-4$, a 4 . In other words, in the order of magnitude evaluation, the new assessed value represents the increase in the risk contribution.

In combining the contribution of different accident sequences to obtain the increase in the core damage probability, 3 of the sequences representing a particular order of magnitude is assumed to 
add up to a probability which is one order of magnitude higher. For example, 3 sequences of value 5 will add up to a 4 , or 3 sequences of value 6 will add up to a 5, and so on. In this order of magnitude evaluation, because of the variability involved in the many parameters that contribute to the accident sequence value, a sequence with a value 5 is roughly approximated as $3.3 \mathrm{E}-5$, and three such sequences will add up to a $1 \mathrm{E}-4$, which is a value of 4 . The choice of the 3.3 is empirically based and is developed comparing the PRA sequences with the notebook sequences. It is also intended to avoid underestimations by the notebook without making it unnecessarily conservative.

The above approach for assessing the risk significance of inspection findings using the notebook for Phase 2 assessment in the SDP is intended to provide an order of magnitude approximation with a bias toward conservative results by the notebook. It can be noted that the Phase 2 process uses an order of magnitude precision to characterize the likelihood of initiating events and credits for mitigating functions. For sequences that include many events, the overall precision of the risk estimate can in some cases become greater than an order of magnitude, given that a bounding bias is being used when assigning numbers for the credits representing the event probabilities. Plantspecific baselining effort was used to refine the assumptions and guidelines to the extent possible to reduce the tendency for the system to become overly conservative, but nevertheless to maintain a bounding property such that chance for the notebook to assess an inspection finding to be risk insignificant when it actually is risk significant is very small. In other words, the approach is maintained conservative such that the chance that a Phase 3 assessment will assess a color for an inspection finding higher than that assessed by the Phase 2 process, i.e., the notebook, is very small compared to the chance that a Phase 2 assessment will assess a color that is higher than that can be assessed in a Phase 3 assessment (false positives are more likely than false positives). In SDP, for cases where a Phase 2 assesses a color GREEN for an inspection finding, no further consideration (i.e., Phase 3 assessment) is necessary. For this use, the conservative approach built in the Phase 2 process through the notebook is deemed acceptable. For cases where the Phase 2 result is WHITE, YELLOW, or RED, a Phase 3 analysis will normally be performed; and its results, which is typically independent of Phase 2 inputs, will be used as the final characterization of risk significance. Thus, any conservatism in those findings will be addressed before a final determination is made in assigning a color to an inspection finding. 


\section{UNIQUE FEATURES OF SDP NOTEBOOKS}

SDP notebooks are specifically designed to support inspectors' needs in understanding and assessing significance of inspection findings. It is also intended to allow a quick screening of the inspection findings so that the inspectors can focus on risk significant findings. To accomplish this objective, the notebooks use the available information about plant systems, plant responses, and from analyses contained as part of plant PRAs in a unique manner. These notebooks can have many uses beyond the use in assessing inspection findings as long as the features are understood and appropriate uses are made.

1. The notebook is a screening tool that is useful to obtain an order of magnitude risk significance and an engineering understanding of the impact of any degradation or temporary unavailability in mitigation features in the plant. The notebook is structured uniquely to provide this information identifying the mitigating functions that are degraded, initiating events where plant response may be impacted, accident sequences that are impacted and may become dominant contributors, and the order of magnitude increase in core damage probability contribution. Order of magnitude increase in large early release frequency (LERF) contribution can also be assessed.

2. The mitigation features in the notebook are rated in terms of numbers ( 2 for a single train of equipment, 3 for a multi-train system, etc.) corresponding to generic reliability of the type of equipment involved. Similar types of equipment are then assigned the same number (or credit) for all plants. The assigned number (or credit) can vary depending on the available redundancy but remains unchanged for different systems across plants as long as the designation of the mitigating feature (e.g., 1 train, 1 multi-train system) remains the same. This approach of assigning credits for mitigating features based on the design characteristics is unique and does not address plant-specific reliability characteristics, but has the advantage of not encumbering the results with data variability and data uncertainty.

3. Consideration of operator actions and credits for such actions are also assigned using an order of magnitude approach where the credits are defined in terms of numbers, similar to the credit for equipment reliability, corresponding to the human error probability. Similar actions across plants of similar design are assigned the same credit. The credit is reduced or adjusted downward if the plant-specific PRA analysis has a higher human error probability which may be due to any difference in plant-specific feature or procedure. In this approach, credit for operator actions is treated consistently and variability in assessing risk significance due to human reliability analyses is reduced.

4. The approach used to assign credits for hardware mitigating features and the operator actions involved makes the SDP notebooks and the results obtained using them insensitive to changes in PRA results due changes in the plant data, i.e., to PRA data updates. In other words, the SDP notebooks are robust because of the way they approach the reliability of equipment and human actions, and are not expected to be changed unless a significant change has taken place in these aspects. 
5. Plant modifications can imply changes to SDP notebooks. Different aspects of the notebook can be affected. They include initiating events modeled, mitigation capabilities, plant response to initiating events, and success requirements. In many such cases, the effort involved in changing is relatively small and can be done quickly. In many cases, changes may be limited within a system and may not even change the mitigation capability characterization. The approach used in the SDP notebook makes incorporation of changes to plant design relatively simple. In other words, updating of the individual notebooks is not expected to be resource intensive.

6. Modeling of plant response to different initiating events depends on the plant designs, plant procedures, and analyses conducted to support possible scenarios. In the SDP notebooks, as mentioned earlier, an attempt is made to model consistently similar design features minimizing plant to plant modeling variation. With this approach, understanding of plantspecific PRA modeling and associated assumptions become significantly easier. In other words, these tools also provide an independent way of assessing the assumptions in the plant's PRA and a means for engineering understanding of the PRA and results obtained from its use. This feature of the SDP notebooks can be used to conduct conventional review of plant-specific PRAs.

7. The approach used in the SDP notebook allows for easier comparison of plants of similar design and of one design to another. In other words, if the evaluation of two plants of similar design results in different significance for an inspection finding, then the SDP tools are useful in understanding the reason for the difference. 


\section{BASIS FOR SELECTION AND CATEGORIES OF INITIATING EVENTS}

The SDP notebook assesses the risk significance of inspection findings considering the initiating events that may occur at a plant, similar to a PRA. The initiating events are selected and are categorized considering their frequency in determining the likelihood of the initiating event for the exposure time of the inspection finding. This aspect of the evaluation is carried out through Table 1 in the notebook. Here, the approach and the reasoning for the information included in Table 1 is discussed.

Table 1 of the notebook includes the initiating events that should be taken into consideration in assessing risk significance of inspection findings and provides the IEL considering the exposure time of the degraded condition identified by the inspection finding. The user can directly look-up the IEL with the knowledge of the exposure time of the degraded condition. The initiating events are grouped considering the frequency of the events as discussed below.

In order to simplify the process and to treat different plants consistently, the approach used in the notebooks divides the initiating events into generic and plant-specific classes. The initiating events modeled in the notebooks can be grouped as follows:

1. The initiating events which are common across pressurized water reactors (PWRs) and boiling water reactors (BWRs) and for which plant-specific data are not available are treated in a generic manner, i.e., they are assumed to have the frequency of occurrence within an order of magnitude based on industry-average values as noted in SECY-99-007A. For these initiators, since plant-specific data are not available or are very limited, differences in their frequency of occurrence beyond an order of magnitude are unlikely. These initiators for pressurized water reactors (PWRs) are: small, medium, and large loss of coolant accidents (LOCAs), Steam Generator Tube Rupture (SGTR), and Main Steam Line Break (MSLB). For boiling water reactors (BWRs), these initiators are: small, medium, and large LOCAs.

2. The initiating events which are common across PWRs or BWRs and for which data are available to justify a generic frequency for the plants are categorized in terms of the generic frequency. Transients (reactor trip) (TRANS) and transients with loss of power conversion system (TPCS) have sufficient data and at the same time show similar characteristics, in terms of frequency, across plant types. They are assigned the same order of magnitude frequency across the plants.

3. Some plant conditions which can occur as part of different initiators and require specific plant responses are treated as separate initiators in the SDP notebooks. Two such cases apply: stuck-open relief valve (SORV) and anticipated transients without scram (ATWS). In plant-specific PRAs, these conditions may be treated as part of different initiators. In the SDP notebooks, they are treated as separate initiators and they are categorized considering their generic frequency across a plant type. SORV frequency for PWR plants varies among the vendor types (Westinghouse [W], Combustion Engineering [CE], and Babcock and Wilcox [B\&W] plants) based on the likelihood of the power-operated relief valve (PORV) being challenged and, accordingly, they are categorized considering the differences. For 
BWR plants, SORV frequency could be grouped within an order of magnitude and is categorized in the same order of magnitude for all BWR plants. ATWS frequency in the SDP notebook considers mechanical failure of control rods, i.e., it is not recoverable by the manual actuation of the reactor trip function or by automatic rod insertion (ARI) for BWRs. (The failure of Reactor Protection System (RPS) circuitry is not modeled in ATWS. An inspection finding relating to the RPS circuitry will require Phase 3 evaluation). Generic ATWS frequency is defined for PWR and BWR plants. Treating these two initiators separately had the added advantage of defining self-contained event tree for the initiators in the notebook, i.e., minimizing the transfers from one event tree to another.

4. In addition to the above initiators, additional plant-specific initiators are considered. These plant-specific initiators are sometimes termed special initiators in PRAs. Many of these initiators are common across the plants but their frequency and plant response may vary depending on plant-specific design and operating procedures. These initiators include loss of offsite power (LOOP), Loss of a DC Bus, Loss of an AC Bus, Loss of Component Cooling Water (LCCW), Loss of Service Water (LOSW), and Loss of Instrument Air (LOIA).

5. A special initiator, LOOP with loss of an Emergency AC Bus (LEAC), is modeled in some PWR plants to supplement the response to LOOP addressed in the LOOP worksheet. This worksheet specifically addresses a SORV condition that may occur in a LOOP where the block valve is unavailable to isolate the breach in the primary from the SORV due to loss of the associated emergency AC Bus.

6. Interfacing system LOCA (ISLOCA) is treated differently compared to other initiators in the SDP notebooks. For ISLOCA, pathways that may lead to these events are noted. The ISLOCA contribution is not considered in assessing the risk significance based on core damage frequency (CDF) impacts.

7. The SDP notebooks for internal events do not include any external initiators, nor internal flooding. Internal flooding is expected to be considered as part of the external initiators and is not explicitly treated in these notebooks. However, some useful information relating to the impact of internal flooding may be gathered as part of the benchmarking of the notebook and such information may be included, usually in Table 2 of the notebook, without modeling the internal flooding initiators.

The intent in categorizing the initiating events in the SDP notebooks is to assure that the applicable initiating events for the plants and the frequency of the initiating events are considered consistently across the plants. To simplify the process and for order of magnitude evaluation, the initiating events may be grouped or combined if such grouping will not affect the assessment of risk significance in the significance determination process. The considerations in grouping the initiating events can be summarized as follows.

1. Different types of initiators requiring different plant responses which involve different mitigating features in the plant are addressed. Different types of initiators include anticipated transients in a plant, different sizes of LOCAs, SGTR in PWRs, MSLB in PWRs, and ATWS. 
2. Special initiators are usually caused by complete or partial loss of support systems. These initiators are considered when they are non-negligible contributors to the plant CDF or have the potential to be non-negligible contributors given an inspection finding for a system train or a component. Special initiators may be combined if the impacts of the initiators are the same, i.e., when no additional risk insight is obtained through modeling them separately. When the contribution of an initiator is negligible, the initiator's impact is the same as that of an initiator already modeled in the notebook, and if significance of any finding for the system whose failure causes the initiator is negligible or Green, then specific modeling of the initiator is not required. A footnote is added as part of system dependency information explaining that a failure of the system causes a plant initiator; however, any finding relating to the components within the system is Green.

3. Special initiators involving loss of one train of redundant trains may be combined into a single initiator if the impact of the losses of the redundant trains are the same and symmetric. If there are differences in the available mitigation capability, i.e., if the impacts are not symmetric, then the loss of separate trains are modeled separately.

4. Special initiators that directly result in a core damage, i.e., where no mitigation capability remains available, are not modeled. Examples of such initiators may be loss of all DCBuses, LOSW, and reactor vessel rupture. Inspection findings identifying such initiators are considered for detailed Phase 3 assessment.

5. Special initiators across plants of similar design are considered to assure adequate treatment of these initiators for each of the plants. If a special initiator is considered for other plants of similar design, but is not considered in a plant's PRA, then it is analyzed and may be included in the SDP notebook unless a justification is defined for its non-applicability.

Table 1 of the notebook includes the information about the initiating events, their grouping, and the assessment of IEL considering the exposure time for the degraded condition.

1. Initiating events are assigned to different rows based on the frequency of occurrence. As discussed earlier, frequency of occurrence of some initiators is based on generic frequency whereas others are based on plant-specific frequency. Each row is defined by a range of frequency representing an order of magnitude. If the frequency of an initiating event is toward the high end of the range of frequency for a particular row, then the initiating event may be assigned to the next higher row. A footnote is provided to explain this placement.

2. Generic frequency used to categorize the initiating events treated generically across plants is based on SECY-99-007A which is obtained from NUREG/CR-5750, "Rates of Initiating Events at U. S. Nuclear Power Plants". This report provides the updated generic frequency estimates for the occurrence of initiating events at U.S. nuclear plants. For the initiating events where plant-specific data are available and the licensee's PRA evaluation justifies a more conservative (i.e., higher) value than the generic categorization defined based on NUREG/CR-5750, the initiating event can be categorized to a row representing a higher 
frequency. This situation typically applies to TRANS and TPCS initiators as they are treated generically, but for these sufficient plant-specific data may exist.

3. Frequency of occurrence of SORV for PWR plants as an initiator, as modeled in the SDP notebooks, depends on vendor type (W, CE, and $\mathrm{B} \& \mathrm{~W})$ which is taken into consideration in deciding the categorization. The frequency of occurrence of SORV depends on two factors: the frequency at which the relief valve is challenged and probability that the valve will fail to seat. Because of the design differences, the frequency of challenges to the relief valve vary considerably from one vendor type to another resulting in different frequency for occurrence of SORV. SORV frequency is considered within the range of 1 per 10-10 $0^{2} \mathrm{yr}$ for $\mathrm{B} \& \mathrm{~W}$ plants, 1 per $10^{2}$ to $10^{3} \mathrm{yr}$ for $\mathrm{W}$ plants, and 1 per $10^{3}$ to $10^{4} \mathrm{yr}$ for CE plants.

4. If the initiating event presented in Table 1 is a combination of multiple initiating events, then the initiating event frequency (IEF) is the sum of the frequencies of the initiating events and the placement is decided on the sum.

5. The frequency of the initiator and the exposure time is considered to obtain the IEL. The exposure times of $<3$ days, $3-30$ days, and $>30$ days are approximated as $1 / 100,1 / 10$, and 1 yr. The frequencies in Rows I, II, III are approximated as $1 \mathrm{E}-1,1 \mathrm{E}-2,1 \mathrm{E}-3$ per year, and similarly for other rows. The product of these terms is used to obtain the IEL presented in the table.

6. If the plant-specific frequency is not available, then the frequency is judged based on the design characteristic of the system involved and the frequency of the loss of similar systems at other similar plants.

Examples of Table 1 for a PWR and a BWR plant are presented to show the categorization of the initiating events in the notebooks (Table 1a and Table 1b). Here, the initiating events whose frequencies are based on generic data and example plant-specific initiators are included. In plantspecific notebooks, plant-specific initiators that are included and their placement will vary depending on plant-specific considerations. 
Table 1a Categories of Initiating Events for a PWR Plant

\begin{tabular}{|c|c|c|c|c|c|}
\hline Row & $\begin{array}{l}\text { Approximate } \\
\text { Frequency }\end{array}$ & Event Type & \multicolumn{3}{|c|}{$\begin{array}{l}\text { Initiating Event Likelihood } \\
\text { (IEL) }\end{array}$} \\
\hline $\mathbf{I}$ & $>1$ per $1-10 \mathrm{yr}$ & Transients (Reactor Trip) (TRANS), Transients Without PCS (TPCS) & 1 & 2 & 3 \\
\hline II & 1 per $10-10^{2}$ yr & $\begin{array}{l}\text { Loss of Offsite Power (LOOP) }{ }^{(1)} \text {, Stuck-open relief valve (SORV) (for } \\
\text { B\&W plants) }\end{array}$ & 2 & 3 & 4 \\
\hline III & 1 per $10^{2}-10^{3} \mathrm{yr}$ & $\begin{array}{l}\text { Steam Generator Tube Rupture (SGTR), Stuck-open Relief Valve } \\
\text { (SORV) (for W plants), Small LOCA (SLOCA), Main Steam Line } \\
\text { Break (MSLB), Loss of Service Water (LSW) }{ }^{(2)}\end{array}$ & 3 & 4 & 5 \\
\hline IV & 1 per $10^{3}-10^{4} y r$ & $\begin{array}{l}\text { Stick-open relief valve (SORV) (for CE plants), Medium LOCA } \\
\text { (MLOCA), Loss of DC Bus D01 (LDCD01) } \\
\text { (LDCD02) }^{(2)} \text {, Loss of DC Bus D02 } \\
\text { (LOIA) }^{(2)}{ }^{(2)} \text { AC Bus A3 (LACA3) }{ }^{(2)} \text {, Loss of Instrument Air }\end{array}$ & 4 & 5 & 6 \\
\hline $\mathbf{V}$ & 1 per $10^{4}-10^{5} \mathrm{yr}$ & Large LOCA (LLOCA) & 5 & 6 & 7 \\
\hline VI & less than 1 per $10^{5} \mathrm{yr}$ & $\begin{array}{l}\text { Anticipated Transients Without Scram (ATWS), Interfacing System } \\
\text { LOCA (ISLOCA) }\end{array}$ & 6 & 7 & 8 \\
\hline & & & $>30$ days & 3-30 days & $<3$ days \\
\hline
\end{tabular}

\section{Notes:}

1. Plant-specific LOOP frequency may differ and its placement is adjusted based on the plant-specific frequency.

2. Examples of plant-specific special initiators. The placement is based on plant-specific frequency. 
Table 1b Categories of Initiating Events for a BWR Plant

\begin{tabular}{|c|c|c|c|c|c|}
\hline Row & $\begin{array}{l}\text { Approximate } \\
\text { Frequency }\end{array}$ & Event Type & \multicolumn{3}{|c|}{$\begin{array}{l}\text { Initiating Event Likelihood } \\
\text { (IEL) }\end{array}$} \\
\hline $\mathbf{I}$ & $>1$ per $1-10 \mathrm{yr}$ & Transients (Reactor Trip) (TRANS), Transients Without PCS (TPCS) & 1 & 2 & 3 \\
\hline $\mathbf{I I}$ & 1 per $10-10^{2}$ yr & $\begin{array}{l}\text { Loss of Offsite Power (LOOP) }{ }^{(1)} \text {, Inadvertent or Stuck-open Relief } \\
\text { Valve (SORV), Loss of Plant Control Air System (LOPCA) }{ }^{(2)}\end{array}$ & 2 & 3 & 4 \\
\hline III & 1 per $10^{2}-10^{3} \mathrm{yr}$ & Loss of Raw Cooling Water (LRCW) ${ }^{(2)}$ & 3 & 41 & 5 \\
\hline IV & 1 per $10^{3}-10^{4} \mathrm{yr}$ & Small LOCA (SLOCA), Medium LOCA (MLOCA) & 4 & 5 & 6 \\
\hline $\mathbf{V}$ & 1 per $10^{4}-10^{5} \mathrm{yr}$ & $\begin{array}{l}\text { Large LOCA (LLOCA), Anticipated Transients Without Scram } \\
\text { (ATWS) }\end{array}$ & 5 & 6 & 7 \\
\hline VI & less than 1 per $10^{5} \mathrm{yr}$ & Interfacing System LOCA (ISLOCA) & 6 & 7 & 8 \\
\hline & & & $>\mathbf{3 0}$ days & 3-30 days & $<\mathbf{3}$ days \\
\hline & & & \multicolumn{3}{|c|}{ Exposure Time for Degraded Condition } \\
\hline
\end{tabular}

\section{Notes:}

1. Plant-specific LOOP frequency may differ and its placement is adjusted based on the plant-specific frequency.

2. Examples of plant-specific special initiators. The placement is based on plant-specific frequency. 


\section{SYSTEMS/COMPONENTS AND DEPENDENCY INFORMATION}

The SDP notebook provides information about systems and their dependencies to help the user in carrying out the assessment of inspection findings. The user is expected to have knowledge of plant systems and have access to system drawings and detailed descriptions. The notebook provides brief information to support the use of the notebook and also includes specific details which may be unique characteristics of the plant and/or are useful for conducting the inspection assessment process.

\subsection{Systems/Components Information to Support Inspection Assessment}

The information is contained in Table 2 of the notebook, called Initiators and System Dependency Table. It contains the following information:

1. A list of the plant systems which play a role in mitigating different initiating events at the plant. Any inspection finding in these systems has the potential to be risk-significant and can be assessed using the notebook. Inspection findings relating to the Reactor Safety Strategic Performance Areas defined in the USNRC's Reactor Oversight Process (ROP) that are screened for further evaluation following the Phase 1 evaluation are expected to be covered by the systems and components included here.

2. Major components in the systems are noted. These components help understand the system dependencies included in the following column. It is not intended to be a detailed list, only types of major components for which inspection findings can be made and that help in understanding the modeling of the initiating events and the mitigation capability of the safety functions are included here.

3. Support systems for the systems included in the table are defined. The intent here is to include the systems whose failure will result in failure of the system it supports.

4. For each of the systems, the applicable initiating events are noted. The applicable initiating events are those where the system plays a mitigating role and/or contributes to the occurrence of the initiating event. This information plays an important role in the assessment of an inspection finding. Corresponding to the systems where an inspection finding has been made, the applicable initiating events define worksheets that need to be evaluated for assessment of the risk significance of the inspection finding.

In addition to including the major components of the system, the following information about the system design characteristics are included:

1. Crosstie capability of the systems are noted. The crosstie capability of a system, usually to another similar system of another unit, is usually credited as part of the mitigation capability and this information is useful in understanding the significance of inspection findings and the modeling used to assess the significance. 
2. Shared systems between multiple unit sites are noted. Any finding on the shared system affects multiple units and is taken into consideration in assessing the significance of the findings relating to these systems. Inspection finding is evaluated for each unit separately.

3. Support systems are either cross-connected or split-train. In a split-train system, each train supports corresponding trains of front-line systems. In a cross-connected system, as the name suggests, the trains are cross-connected and a functioning train will support the trains of the front-line systems. The requirements of which initiating events are to be assessed for an inspection finding in these systems depend on whether the system is cross-connected or split-train. In addition, the SDP Usage Rules are defined in terms of cross-connected and split-train systems. Defining cross-connected and split-train systems helps the inspectors in understanding the process used for the assessment of inspection findings relating to these systems.

\subsection{Use of Dependency Information}

The approach used to include the support system or system dependency information can be summarized as follows:

1. The systems included as support systems are those that can result in failure of components, trains, or of the entire system. In other words, complete dependency is considered. Partial dependency, i.e., where additional failure will be needed for failure of the system, is not included, but may be noted in a footnote.

2. If there is a backup to the support system, then a footnote is provided defining the availability of backup and the manual actions involved. The footnote may also include the treatment of the backup action in the plant PRA, particularly if it is not modeled in the PRA.

3. Electrical power dependency is noted in terms of emergency or safety power vs. nonemergency or non-safety power. Noting such dependencies helps understand the modeling and systems credited in different initiators, particularly in special initiators.

4. For reactor coolant pump (RCP) seals in PWRs, the seal cooling requirements are noted as part of the RCP seal support systems. In the notebook, the interest on RCP seal primarily focuses on RCP seal LOCAs and the loss of the support systems that can cause such LOCAs. The potential for RCP seal LOCAs due to loss of the support systems is modeled in applicable initiating events.

5. System dependency information does not include component-specific or train-specific information. Providing such information can be useful, but would make the dependency table cumbersome and complicated. Such complicated tables can distract from the specific use of the notebook in assessing inspection findings. Such details are expected to be obtained from the plant-specific documentation available to the inspectors.

The information provided in the table is supplemented with additional information to support the assessment of inspection findings, as discussed below. 
1. The plant CDF for internal initiators excluding internal flooding is noted along with the corresponding version of the plant PRA. The plant CDF provides a perspective on the risk significance of the inspection finding being assessed.

2. Unique information relating to the system design and the support system that can aid in the assessment of inspection findings is included, as considered appropriate.

3. Battery capacity varies from plant to plant and the capacity (in terms of hours) when battery chargers are not available is noted. This helps explain the plant response to loss of offsite power events. Battery charger capacities also differ from plant to plant. In some plants, battery chargers can carry the safety injection (SI) loads without the batteries. Such information is noted along with how battery findings should be evaluated depending on whether battery chargers can carry SI loads or not.

4. For emergency diesel generators (EDGs), the diesel day tank capacity is noted, i.e., how long the day tanks can support EDG operation without EDG fuel oil transfer pumps. This information is provided to help inspectors assess inspection findings relating to fuel oil transfer pumps.

5. Room cooling or heating, ventilation, and air conditioning (HVAC) requirements are discussed based on the evaluation conducted or assumptions used in the plant PRA. Room cooling requirements are included in the table consistent with the plant PRA assumptions. If room cooling is not required based on plant PRA assumptions, it is so noted. Room cooling requirement may vary depending on the time of the year, i.e., a room may need cooling during warm weather, and not during cool weather. For such cases, a footnote is used in the notebook to clarify the cooling requirements.

6. Differences in assessment of risk significance by the notebook compared to the plant-specific PRA are identified. As part of the benchmarking of the notebooks, risk significance of a select set of components and operator action was assessed using the notebook and compared with the plant-specific PRA evaluations. Under and overestimations by the notebook are identified in the notebook with a brief explanation of the reasons for the differences. The reasons for under and overestimations are useful in defining and explaining the risk significance of the inspection findings.

\subsection{Defining Applicable Initiating Events for Assessment of Inspection Findings}

Following identification of the inspection finding and the systems/functions it may affect, the initiating events to be evaluated to assess the inspection finding need to determined. In general, the initiating events whose frequency may be impacted by the finding and/or for which the systems/functions impacted by the inspection finding play a mitigating role need to be evaluated. For the notebook evaluation, this implies the worksheets corresponding to the initiating events will need to be evaluated. To aid the user in this process, Table 2 of the notebook identifies the worksheets to be evaluated for findings corresponding to each of the systems. 
The process for identifying the applicable worksheets involves identifying the safety functions to which the affected systems/components contribute and identifying the worksheets where those functions are called for. In addition, if the affected systems/components contribute to the occurrence of an initiating event, then the worksheets for those initiating events are also included. Comparable to a PRA analysis, the intent is to identify those initiating events whose contributions can become important in determining the risk significance of the degraded condition identified by the inspection finding. In the worksheets, the mitigation capability typically identifies the front-line system trains needed for the function. This information provides a useful link to identifying the initiating events and corresponding worksheets to be evaluated. However, for support systems, identifying the applicable initiating events becomes somewhat complicated because of the need to identify the frontline systems/components supported by the support system being considered.

The approach used in identifying the worksheets to be evaluated corresponding to inspection findings in each of the systems can be summarized as follows:

1. For front-line systems, the applicable worksheets are defined considering the initiating events where these systems are called for in the mitigation role.

2. For support systems, the identification of the applicable initiating events depends on the system design and how the system failures are modeled in the worksheets.

(a) If a special initiator is included representing the loss of the system and the systems is crosstied, then only the special initiator is evaluated. Any failure in the system impacts the likelihood of the system failure without directly affecting any of the front-line systems. Assessment of the special initiator provides the risk significance of the components within the system.

(b) If the system is split, i.e., one train of the system supports one train of the safety systems, then evaluating only the special initiator involving the loss of the support system is not sufficient. Combinations of failures involving one train of the support system and a different failure (not caused by the support system) in other initiating events can be important contributors. In such cases, along with the special initiator involving the loss of the support system, other initiators where the systems supported by the support system play a mitigation role are included.

3. Some cases exemplifying the consideration and/or requiring special consideration in defining the applicable initiating events for evaluation are discussed below.

(a) For EDGs, the LOOP and LEAC worksheets are usually evaluated. LEAC worksheet is not needed for many plants; in those situations, only the LOOP worksheet may be evaluated. In some plants, there are special initiators involving loss of a portion of the electrical power supply requiring activation of EDGs. In those plants, these special initiators are also evaluated along with the LOOP and LEAC worksheets.

(b) For loss of one AC or DC bus, typically all the initiators are evaluated. Loss of one of the buses will fail one train of multiple systems and combinations of a bus failure 
resulting in failure of one train of the system with failure of the other train due to other causes in different initiators can be important contributors. Typically, all initiators have systems requiring $\mathrm{AC}$ and $\mathrm{DC}$ power.

(c) RCP seal failures in PWRs are assumed to lead to SLOCA. For a finding on RCP seal, the SLOCA worksheet is evaluated.

(d) In the notebook for BWRs, the PCS combines both the steam and feed path in a single function. The applicable initiating events to be evaluated for the steam and feed path are different. For the steam path, the transient with loss of PCS (TPCS) along with other initiating events where feed path is modeled and requires steam for their operation are considered. For the feed path, all applicable initiators where the feed path is modeled in a mitigation role are considered. For an inspection finding on the feed path, impact on the initiating event frequency, i.e., on the TPCS frequency, is considered negligible and is not considered. 


\section{GENERAL RULES AND BASIS FOR DEVELOPING THE WORKSHEETS USED FOR ASSESSMENT OF INSPECTION FINDINGS}

In the SDP notebook, worksheets are provided for each of the initiating events applicable for the plant. These initiating events are also defined in Table 1 of the notebook. The initiating events defined in Table 1 and the worksheets defined as part of Table 3 correspond to each other, i.e., for each initiating event in Table 1, a worksheet is available, and vice-versa.

The worksheets are designed to assess the risk significance of an inspection finding and to obtain an engineering understanding of the significance. To achieve these objectives, the worksheets are designed with specific information. The information included and the basis for including them are as follows:

1. The safety functions needed to respond to the initiating event are defined. Plant response to the initiating event is defined in terms of an event tree, and the safety functions defined in the event tree are the needed safety functions. The event tree developed for each initiating event is similar to the event trees developed for the small event tree-large fault tree approach (as opposed to large event tree-small fault tree approach), typically developed in a PRA. The event tree headings or safety functions defined involve the front-line systems needed to mitigate the conditions that may arise from the initiating event. The event tree for each of the initiating event is included in the notebook. These event trees provide an understanding of the modeling of the plant response to the initiating events and specifically, the accident sequences defined for each of the initiating events.

2. Mitigation capability of each of the safety functions is defined in terms of the success requirements at the train level, i.e., minimum number of equipment or trains needed to carry out the function and the available number of equipment or trains. The success requirements for each of the safety functions are based on the plant-specific PRAs, modified in some cases by the SDP assumptions specific to that type of plant as discussed in Chapter 9 .

In addition, the mitigation capability is designated using the redundancy available and reliability of the operator action. These designations help define the credits applicable for the function and provide the basis for the assessment of the significance of the finding when the mitigation capability is degraded. If the mitigation capability, i.e., the safety function, is actuated automatically, then the mitigation capability is designated by the hardware designation such as 1 train, or 1 automatic steam-driven train or 1 multi-train system.

If the mitigation function requires an operator action, it is designated as an operator action. Only in cases where the operator action is more reliable than the reliability of the hardware involved, the mitigation credit may be defined in terms of the hardware credit even if an operator action is involved. Usually, operator action credit determines the credit for the function and it is determined by the applicable operator action credit. When the hardware and operator action credits are of the same order of magnitude, then the operator action credit is noted. 
3. Accident sequences that can result from the particular initiating event are defined in the worksheet. The accident sequences are developed based on the event tree presented for the initiating event considering the Boolean reduction process. The accident sequences are presented in terms of the safety functions defined and are used to assess the significance of the inspection findings.

4. The accident sequences are evaluated using the designations defined for the safety functions and the IEL rating. The designations assigned for different functions are associated with values (credits) which are combined with the IEL to obtain a value for the accident sequence. Given an inspection finding, the mitigation capability of the function is affected changing the value of the function. The changed value is used to obtain the contribution of the accident sequence to the risk significance of the inspection finding. To assist the user in assessing the risk significance, the worksheet provides the basecase value of each accident sequence considering the IEL for exposure time $>30$ days and full creditable mitigation capability of each of the functions involved.

5. The basecase value defined for an accident sequence approximates the contribution of the sequence to core damage when none of the mitigation capabilities is known to be degraded. A basecase value of 6 for an accident sequence approximately corresponds to $1 \mathrm{E}-6$, i.e., the likelihood of occurrence of the accident sequence is 1 in 1E6. Given an inspection finding, the accident sequence value may change to 5 representing an increased likelihood of the accident sequence due to reduced mitigation capability as revealed by the inspection finding. The new value representing the increase in likelihood of the accident sequence is used to assess the risk significance of the inspection finding.

6. Footnotes may be included for each of the worksheets to provide worksheet-specific information that may assist the inspector or user. Footnotes are intended to clarify the information contained in the worksheet, i.e., the safety function definition, mitigation capability, designation of hardware and operator action credit. Often, the footnote will provide the human error probability (HEP) associated with an operator action, particularly if the HEP is higher than the generic operator action credit for the action.

In addition, for the special initiators, a footnote is used to describe the initiator and its impact on the mitigation capability. It includes the frequency of the initiator and refers to the applicable event tree if the initiator-specific event tree is not provided. In selected cases, footnotes may also refer to differences with plant-specific PRA modeling as they may help explain the difference in rịsk-significance of inspection findings between the plant PRA and the SDP notebook. 


\section{BASIS FOR MODELING RESPONSES TO INITIATING EVENTS}

Plant response to each of the initiators defined in the Initiating Event Table (Table 1) is modeled considering the safety functions similar to that defined in a PRA. For each initiator, the safety functions are defined in terms of the system trains available to achieve the necessary function including the success requirements and the need for operator actions.

\subsection{Safety Functions}

Safety functions are defined based on systems performing a safety function and are typically consistent with the functions defined in the plant-specific PRAs. To assure consistency across similar plant types, a similar definition is maintained unless there is a plant-specific difference that justifies an alternate definition of the safety function. In some cases, a particular operator action (e.g., tripping RCPs, or recovering AC power after LOOP) may be defined as a safety function. Examples of safety functions are auxiliary feedwater (AFW) system for secondary heat removal (SHR), high pressure injection (HPI), and Reactor Coolant System (RCS) depressurization (RCSDEP). Specific basis for defining safety functions and their consideration in accident mitigation is discussed for each of the initiators in Chapter 9. For a specific notebook, consistency in safety function definition is maintained across different initiating events. For example, when HPI is defined as a safety function, the same name/designation is maintained for high pressure injection for different initiators; for special initiators, the same definition is maintained but the mitigation capability may change also changing the assoated credit, since the capability, e.g., the available number of trains, may be limited because of the initiator.

\subsection{Creditable Mitigation Capability}

The creditable mitigation capability is defined in terms of the system trains considering the plantspecific success criteria as used in the plant PRA. It is typically defined in terms of the front-line systems without the support systems. If the systems' trains have different characteristics such that their mitigation credit will be different, then these trains are separately defined. For example, the motor-driven and steam-driven trains of AFW system are separately defined.

Mitigation capability as defined in the plant PRA and in the plant procedure are considered for the SDP model. The following considerations apply:

1. If the mitigation capability used is not consistent with other similar plants, then it may not be credited. The reasoning is to maintain the conservative approach in the SDP screening tool and to provide for an opportunity for further evaluation of the specifics in the Phase 3 evaluation.

2. If the mitigation capability requires an operator action and has an assessed error probability of 0.5 or higher, then it is not credited and a footnote is added that such a mitigation capability is available but the operator error probability is high. Crediting operator action with an error probability higher than 0.5 is considered not relevant for a screening tool and may have the potential to distort results. 
3. If the mitigation capability is available and is proceduralized but not modeled in the plant PRA, then it may not be credited. In some situations if it is judged that it is an oversight or an unnecessary conservatism in the PRA, then it may be modeled. Otherwise, it is judged that if the PRA review has considered it inappropriate for credit, then the credit does not apply.

4. If the mitigation capability is yet to be proceduralized but has been credited in the PRA, then it may not be credited in the SDP model. Non-proceduralized functions may not be credited in assessment of inspection findings and, accordingly, they are not credited in the SDP models.

\subsection{Creditable Mitigation Capability: Hardware vs Operator Failure}

Each mitigation capability is assigned a hardware or an operator failure designation to facilitate the risk significance evaluation of an inspection finding considering the remaining mitigation capability. The hardware designations are 1 train, 1 automatic steam-driven (ASD) train, and 1 multi-train system. Operator action credits are defined as 1,2, and 3 corresponding to a HEP of $1 \mathrm{E}-1,1 \mathrm{E}-2$, and $1 \mathrm{E}-3$ respectively. If the safety function is automatically actuated, then it is given a hardware designation. If an operator action is needed for the action or part of the action, then it is designated as an operator action. Some exceptions apply, as discussed below.

1. If the capability is dominated by the failure probability of the operator, then the credit for the operator action determines the mitigation credit.

2. If the capability is dominated by hardware failure and the operator failure probability is an order of magnitude lower than the hardware failure contribution, then the limiting credit of the hardware failure is used to credit the mitigation capability. A footnote is written to note that an operator action is needed for the function.

3. If the hardware and operator failure contributions are comparable, then the mitigation credit is defined in terms of the operator action credit.

\subsection{Hardware Failures: Consideration of Common-cause Failures and Dependency on Support Systems}

Hardware failures are defined at the train level considering potential for common cause failures. Trains consisting of passive components are treated similarly even though passive components have a lower likelihood of failure.

A train composed of pumps and valves which are electrically operated along with associated actuation circuitry and support systems is defined as 1 train with a credit of 2 corresponding to an unavailability of $1 \mathrm{E}-2$.

A system composed of two or more similar trains is designated as 1 multi-train system with a credit of 3 equivalent to an unavailability of $1 \mathrm{E}-3$. This designation is based on the consideration of common-cause failure of the components within the redundant trains. In this designation, two or 
more trains are assigned the same credit which implies a complete dependence beyond two trains. In other words, given a failure of the first two trains, the remaining trains are assumed to fail. This is usually conservative and leads to assessment of higher significance when more than two trains are available for mitigation.

A system composed of two trains that are not considered to be susceptible to common cause failure modes is considered a system of diverse trains. The probability of this equipment being unavailable due to failure, test, or maintenance is approximately $1 \mathrm{E}-4$, and a credit of 4 apply.

Steam-driven trains, e.g., turbine-driven AFW pumps in a PWR, high pressure coolant injection (HPCI) or reactor core isolation cooling (RCIC) in a BWR, are designated as 1 ASD train considering the higher unavailability associated with these components. One ASD train is assigned a credit of 1 corresponding to an unavailability of $1 \mathrm{E}-1$.

Diesel-driven trains are designated as 1 train, similar to electrical powered trains. If a diesel-driven train is shown to have a higher unavailability compared to an electrical powered train, and a credit of 1 may be assigned, as opposed to a credit of 1 train, with an explanation in the footnote.

Similar to diesel-driven trains, sometimes a credit of 1 is assigned considering higher unavailability of some components and trains. This may usually involve trains/components in some specific conditions resulting in higher unavailability, e.g., components in harsh environment, components requiring excessive maintenance. Justification for assigning a credit of 1 is presented in a footnote.

Table 2 of this document presents a summary of the mitigation capability rating value.

In addition to the above consideration, dependency of the front-line systems to a common support system may limit the allowable credit. Consider a safety function consisting of two separate systems but with a dependency to the same support system. In this case, because of the dependency to the same support system, the credit is limited by the credit of the support system as opposed to the combined credit of both systems. Consider that containment heat removal can be accomplished either by the containment spray system or by the fan coolers. Both containment spray and fan coolers are multi-train systems, but each depend on component cooling water (CCW) which is also a multi-train system. The credit for the containment heat removal will be 1 multi-train system because of the CCW system, as opposed to 2 multi-train systems because of dependency of both systems on the $\mathrm{CCW}$ system. Hypothetically, if the fan coolers were supported by an alternate system, then the credit of 2 multi-train systems could be assigned.

\subsection{Operator Action Credit}

Operator action credit is based on the assessed HEP for the action. As noted in Table 2 of this document, different ranges of HEPs are used to designate different operator action credits.

The HEP for a particular operator action is based on a survey of similar actions at similar plants. The intent in defining the operator action credits are as follows: 
1. HEPs for similar actions across similar plants are expected to be similar, i.e., within the same order of magnitude. To treat the plants consistently, credits for operator actions should be consistent and low probabilities should be justified based on specific plant designs and procedures.

2. HEP below 1E-4 (credit $=4$ ) is expected to be associated with large uncertainty and is limited to approximately $1 \mathrm{E}-3$, i.e., a credit of 3 . In other words, operator action credit higher than 3 can only be provided in exceptional cases.

3. A HEP of 0.5 or higher is considered a highly improbable operator action, i.e., a failure of the operator action is assumed. In other words, the actions whose probability is judged to be 0.5 or more are not credited.

4. A HEP of 0.1 is assumed for operator actions to recover failed equipment that is capable of being recovered after an initiating event occurs. Action may take place either in the control room or outside the control room.

With these objectives, the approach used to define operator action credit is to survey similar actions at similar plants and obtain an "average value" to define the credit. The average value is obtained by taking a geometric mean of the HEPs obtained from the plant-specific PRAs for similar actions at similar plants. The credits defined for different operator actions based on the survey of the HEPs across the plants are presented in Appendix B. In this approach, plants whose HEPs are optimistic compared to the average credit receive the average credit and the variation in the assessment of risk significance due to the variability in the HEPs is minimized.

The approach in assigning the operator action credits based on assessed average value for the HEP is as follows:

1. If the plant-specific HEP is lower than the assessed generic credit, then the generic credit is use.

2. If the plant-specific HEP is higher than the assessed generic credit, the credit is defined based on the plant-specific HEP.

3. If the operator action is plant-specific for which no generic credit is available, then the plant HEP is used to define the operator action credit. 
Table 2 Remaining Capability Rating Value

\begin{tabular}{|c|c|}
\hline Type of Remaining Capability & $\begin{array}{c}\text { Remaining } \\
\text { Capability } \\
\text { Rating } \\
\text { (Credit) }\end{array}$ \\
\hline $\begin{array}{l}\text { Recovery of Failed Train } \\
\text { Operator action to recover failed equipment that is capable of being recovered after an } \\
\text { initiating event occurs. Action may take place either in the control room or outside the control } \\
\text { room and is assumed to have a failure probability of approximately } 0.1 \text { when credited as } \\
\text { "Remaining Mitigation Capability." Credit should be given only if the following criteria are } \\
\text { satisfied: (1) sufficient time is available; (2) environmental conditions allow access, where } \\
\text { needed; (3) procedures exist; (4) training is conducted on the existing procedures under similar } \\
\text { conditions; and (5) any equipment needed to perform these actions is available and ready for } \\
\text { use. }\end{array}$ & 1 \\
\hline $\begin{array}{l}1 \text { Automatic Steam-Driven (ASD) Train } \\
\text { A collection of associated equipment that includes a single turbine-driven component to } \\
\text { provide } 100 \% \text { of a specified safety function. The probability of such a train being unavailable } \\
\text { due to failure, test, or maintenance is assumed to be approximately } 0.1 \text { when credited as } \\
\text { "Remaining Mitigation Capability." }\end{array}$ & 1 \\
\hline $\begin{array}{l}1 \text { Train } \\
\text { A collection of associated equipment (e.g., pumps, valves, breakers, etc.) that together can } \\
\text { provide } 100 \% \text { of a specified safety function. The probability of this equipment being } \\
\text { unavailable due to failure, test, or maintenance is approximately } 1 \mathrm{E}-2 \text { when credited as } \\
\text { "Remaining Mitigation Capability." }\end{array}$ & 2 \\
\hline $\begin{array}{l}1 \text { Multi-Train System } \\
\text { A system comprised of two or more trains (as defined above) that are considered susceptible to" } \\
\text { common cause failure modes. The probability of this equipment being unavailable due to } \\
\text { failure, test, or maintenance is approximately } 1 \mathrm{E}-3 \text { when credited as "Remaining Mitigation } \\
\text { Capability," regardless of how many trains comprise the system. }\end{array}$ & 3 \\
\hline $\begin{array}{l}2 \text { Diverse Trains } \\
\text { A system comprised of two trains (as defined above) that are not considered to be susceptible } \\
\text { to common cause failure modes. The probability of this equipment being unavailable due to } \\
\text { failure, test, or maintenance is approximately 1E- } 4 \text { when credited as "Remaining Mitigation } \\
\text { Capability." }\end{array}$ & $4(=2+2)$ \\
\hline $\begin{array}{l}\text { Operator Action Credit } \\
\text { Major actions performed by operators during accident scenarios (e.g., primary heat removal } \\
\text { using bleed and feed). These actions are credited using three categories of human error } \\
\text { probabilities (HEPs). These categories are Operator Action }=1 \text { which represents a failure } \\
\text { probability between } 5 \mathrm{E}-2 \text { and } 0.5 \text {, Operator Action }=2 \text { which represents a failure probability } \\
\text { between } 5 \mathrm{E}-3 \text { and } 5 \mathrm{E}-2 \text {, and Operator Action }=3 \text { which represents a failure probability } \\
\text { between } 5 \mathrm{E}-4 \text { and } 5 \mathrm{E}-3 \text {. }\end{array}$ & 1,2 , or 3 \\
\hline
\end{tabular}




\section{MODELING RESPONSE TO INITIATING EVENTS FOR EACH REACTOR TYPE}

In this section, the modeling of the plant response to different initiating events is discussed. Separate discussion is provided for each of the reactor types. Discussion of PWR plants is presented separately for Babcock and Wilcox (B\&W), Combustion Engineering (CE), and Westinghouse (W) designs. General Electric (GE) BWR plants are discussed separately. The intent here is not to present a detailed discussion of the plant responses to different initiators, rather a knowledge of plant response to initiators, emergency operating procedures, and treatment of initiators in PRAs is assumed. Here, the focus is on modeling assumptions and treatment of plant-specific features and analyses. The aspects that are similar across the plants of similar design are emphasized to achieve consistent modeling and to minimize variation due to modeling differences. Unique plant-specific features requiring special treatment are discussed within the plant-specific notebooks.

\subsection{Pressurized Water Reactors: Babcock and Wilcox (B\&W) Plants}

\section{Transients (TRANS)}

The transient events include those events which result in reactor trip followed by failure to bring the reactor to safe shutdown. The sequences primarily involve failure to remove decay heat either by steam generator cooling or by primary system feed and bleed cooling.

1. Following a transient, main feedwater (MFW) flow is maintained but operator action is needed to maintain the steam generator (SG) level. Multiple redundancies consisting of turbine-bypass valves (TBVs), atmospheric dump valves (ADVs), and main steam safety valves (MSSVs) are available for the steam relief path. Considering the operator action for maintaining the SG level, the PCS function is modeled with an operator action.

2. In the B\&W plants, a portion of the SHR using EFW or AFW may require manual action. These alternate means of SHR provide added redundancy but a delay in operation of this equipment can result in opening of safety relief valves (SRVs) with a probability of 0.1 for failure to reclose under a liquid release. Considering the limited time available to carry out these actions, the operator action credit for this equipment is limited to 1.

3. For feed and bleed cooling at B\&W plants, often referred to as HPI cooling, operator action may not be necessary for most $B \& W$ plants. $B \& W$ units have HPI pumps with shutoff heads above the SRV setpoint and even if the operator does not open the PORV or electromatic relief valve (ERV), HPI will automatically actuate and the feed and bleed cooling will occur at the SRV setpoint. Davis-Besse has a shutoff head near the SRV setpoint and the operator action is assumed necessary to open the PORV for cooling to succeed. In modeling operator action for the feed and bleed action, operator action in controlling the HPI flow is considered.

4. In these plants, operator action is required to initiate high pressure recirculation (HPR) where HPI trains draw suction from the low pressure injection (LPI) trains. 
5. Containment cooling to prevent core damage is not required unless the plant-specific PRA has defined such a requirement.

\section{Transients With Loss of Power Conversion System (TPCS)}

These transients involve loss of the PCS that results in the reactor and turbine trip, e.g, loss of feedwater, loss of condenser vacuum, and loss of support systems leading to loss of the PCS. The modeling is similar to TRANS except that PCS is not credited.

\section{Small LOCA (SLOCA)}

An SLOCA includes break sizes where normal makeup is not sufficient to maintain RCS inventory and at the same time, full removal of decay heat cannot be achieved. An SLOCA will lead to a reactor trip and the continued decrease in RCS pressure will lead to automatic actuation of the HPI system to maintain RCS inventory. The considerations in SLOCA modeling are as follows:

1. If the SG cooling is available, RCS inventory is maintained by HPI and long term cooling is provided by HPR which requires initiation prior to borated water storage tank (BWST) depletion. MFW is usually not credited since it is not certain that the system will function under the reduced pressure conditions in the RCS and SG.

2. In B\&W lowered loop plants (i.e., all the plants except for Davis-Besse), certain sizes of SLOCA will require increased flow of emergency feedwater (EFW) to maintain the SG level high to assure natural recirculation. Failure to do so may result in loss of natural recirculation requiring the operator to initiate feed and bleed. The action involved in this condition may be called operator actions to maintain SG level.

3. If adequate feedwater was not available, then feed and bleed cooling could be accomplished through a pressurizer relief path and HPI/HPR can provide the core cooling.

4. In an SLOCA if HPI is not available, it is assumed that core damage will occur. In such a situation, the operator could, and probably would, cooldown the RCS with the steam generators to allow shutdown cooling to be established using the LPI system. This is not credited in the B\&W plant-specific PRAs and, also, not in the notebooks.

\section{Stuck-Open Power-Operated Relief Valve (SORV)}

In the B\&W plants, PORVs are demanded during the transients or as a result of improper operation of high head makeup pumps. In addition, a pressurizer safety valve (PSV) can also be demanded in certain situations. The is mainly due to high shutoff head of the makeup pumps, smaller free volume in the pressurizer, and smaller inventory in once-through steam generator in B\&W plants. Transient/SLOCA events followed by delayed operation or failure of both MFW and EFW; improper operation of makeup/HPI pumps; and turbine trip followed by failure to control SG pressure by TBVs or SG ADVs/MSSVs can cause a PSV to open and possibly stick. A stuck-open PSV is modeled as part of the SLOCA initiator or other initiators, if it is a significant plant-specific contributor. A stuck-open PORV (SORV) is modeled as a separate initiator (with a separate 
worksheet). Considering the higher demand for PORVs in a B\&W plant and the likelihood of PORVs to stick open, the frequency of this initiator is assessed to be higher compared to other PWR plants and this initiating event is placed in Row II of Table 1. The considerations in modeling the SORV for B\&W plants are summarized as follows:

1. Timely closing of the associated block valve is assumed to continue progression of the event similar to the transient initiator where the situation occurred. Additional modeling of the event was not necessary.

2. On failure to close the block valve, the initiating event is similar to SLOCA and SLOCA modeling considerations apply.

3. Since a loss of feedwater event or a loss of offsite power may be the initiator that resulted in the SORV, PCS is usually not credited in this event.

\section{Medium LOCA (MLOCA)}

In an MLOCA, the flow is sufficient to remove decay heat (i.e., heat removal via SG is not needed), but makeup from the HPI would be required to avoid core uncovery.

1. In an MLOCA, failure of HPI is assumed to lead to a core damage. RCS depressurization is not considered timely for LPI to function as early injection to maintain coolant inventory.

2. In the longer term, HPI operation in the high pressure recirculation mode is adequate to maintain core cooling. The LPI system is needed to provide a continuing source of suction to the HPI pumps.

\section{Large LOCA (LLOCA)}

An LLOCA is characterized by rapid blowdown to containment until the pressure in the RCS essentially reaches equilibrium with the containment. As the RCS pressure is dropped, core flood tanks (CFTs) will inject followed by LPI injection and operation of LPI system in the recirculation mode (LPR).

1. Success of CFT is assumed necessary in a LLOCA. CFT may not be required for all LLOCA sizes, but assumption of its requirement is conservative and consistent with plant-specific PRA models. For B\&W. designs, CFTs directly inject into the vessel and therefore, none of the two CFTs is lost due to the LLOCA.

2. Following success of CFT, LPI is needed and failure of LPI leads to core damage. In the longer term, operator action is needed to switch the suction to the reactor building sump prior to depleting the BWST. 


\section{Loss of Offsite Power (LOOP)}

A LOOP places a demand on the emergency power sources to start and to supply the loads necessary for establishing stable shutdown conditions. A LOOP creates special conditions on the availability of the systems required to maintain RCS integrity and core decay heat removal. Considerations in modeling the LOOP initiator involves addressing the special conditions, e.g., emergency power availability including alternate $\mathrm{AC}$, recovery of offsite power, $\mathrm{RCP}$ seal cooling requirement and seal LOCA considerations, and SBO coping capability.

1. Following successful operation of emergency $\mathrm{AC}$ in a LOOP, the event progression is similar to a transient with a loss of power conversion system (TPCS). The RCPs are tripped and the seal cooling is provided by the HPI or other cooling sources supported by emergency power.

2. In a station blackout (SBO) condition with emergency feedwater sources not dependent on AC power available, if alternate sources of seal cooling are not available, the possibility of seal LOCA is considered based on the type of the RCPs and the associated seals.

3. For the Byron-Jackson (BJ) type of pumps, closing of the seal bleed-off line by the operator may be needed to avert a seal LOCA. Treatment of seal LOCA is presented in Sections 9.2 and 9.3 respectively for $\mathrm{BJ}$ and $\mathrm{W}$ pumps.

4. In an SBO condition, non-AC dependent emergency feedwater sources (turbine-driven or diesel-driven emergency feedwater pumps) can successfully terminate the accident, if seal LOCA does not occur. However, continued operation of these pumps may be limited by the unavailability of instrumentation due to loss of battery. Recovery of offsite power or alternate sources to assure the availability of instrumentation is modeled as applicable. The time to recover offsite power may also be determined by seal LOCA, if that is assumed to occur, or other plant-specific considerations that may apply.

5. In an SBO condition with non-AC dependent emergency feedwater sources not available, recovery of offsite power is needed within a short time, 1 to 2 hours, to avert core damage. SG dry-out will be followed by a core damage.

6. Following recovery of offsite power where SG dry-out is experienced, i.e., in an SBO condition with non-AC dependent emergency feedwater sources unavailable, emergency feedwater can be credited based on plant-specific analysis. Otherwise, feed and bleed cooling is assumed to be required.

\section{Steam Generator Tube Rupture (SGTR)}

SGTR can be considered a special case of SLOCA with the important difference being that RCS inventory is lost through the secondary and bypasses the containment. In such situations, the primary response is to cooldown and depressurize the RCS below the affected steam generator MSSV setpoint so that leakage from primary to secondary is terminated and long term cooling can be achieved. Also, if the SG isolation does not occur (e.g., due to failure of a MSSV to close), then because of continuous inventory loss through the steam generator, inventory in the BWST may not 
be adequate for long term cooling by recirculation. BWST makeup will be required. The considerations in modeling SGTR for B\&W plants can be summarized below.

1. In lowered loop B\&W plants (i.e., all plants except for Davis-Besse), failure of HPI following a SGTR can be assumed to lead to core damage.

2. When the faulted SG is isolated and primary to secondary leakage has been terminated by RCS depressurization below the MSSV setpoint, both shutdown cooling and BWST makeup can be credited.

3. When the faulted SG is isolated, feed and bleed cooling with the PORV and long-term cooling using HPR can be accomplished.

4. When the faulted SG is not isolated due to operator failure to isolate or MSSV failing to reseat, BWST refill will be needed to supplement the inventory in the containment sump. BWST refill can be credited based on plant-specific PRA analyses.

\section{Main Steam Line Break (MSLB)}

MSLBs introduce overcooling to the RCS. Severity of the overcooling may result in a pressurized thermal shock (PTS) to the vessel. Plant-specific PRAs usually do not consider the PTS, but in the SDP notebook PTS is considered making the modeling different from plant-specific PRAs. In modeling the MSLB, considerations used addressing the PTS issues are as follows:

1. Closure of all the main steam isolation valves (MSIVs) will terminate the event similar to a transient with loss of the power conversion system (TPCS). The added consideration is the need to stop the high head injection (see item 4 below).

2. Failure of two or more MSIVs is assumed to lead to core damage due to PTS.

3. In a situation where one of the MSIVs has failed to close, operator action may be needed to terminate the HPI and to isolate feedwater.

4. Following successful initiation of HPI and EFW, operator action is needed to terminate high head injection. Failure of the operator to take this action will result in forced opening of the PORV and possibly the PSVs requiring HPR. This situation applies both when one or none of the MSIVs has failed to close.

5. MFW is conservatively assumed to be unavailable due to the impact of this transient on the secondary side of the plant. 


\section{Anticipated Transients Without Scram (ATWS)}

Transient with failure to trip the reactor is modeled separately in the notebook without modeling as part of each initiator. Loss of MFW was assumed to be a limiting situation for ATWS and therefore, ATWS is modeled considering loss of MFW as the transient where the reactor failed to trip. ATWS is only modeled for the conditions where the moderator temperature feedback is favorable. When moderator temperature feedback is unfavorable, core damage is assumed to occur, i.e., mitigation capability does not apply. Inspection findings relating to the mitigation capabilities that apply in ATWS when moderator temperature feedback is favorable is assessed with slightly conservative risk significance because of this approach. In other words, the implicit assumption is that moderator temperature feedback is favorable at all times giving the equipment and actions in the mitigation capability higher risk significance.

1. $\quad B \& W$ plants have a diversified scram system which is credited to trip the turbine.

2. SHR through the emergency feedwater is modeled considering auto-actuation of the EFW pumps. Emergency or auxiliary feed pumps requiring manual actions are not credited considering the limited time available. Steam relief requirements in ATWS may be more restrictive compared to transients and such requirements are explicitly considered.

3. Primary pressure relief requirements can vary depending on the time in the fuel cycle when the event occurred. A conservative approach is used where the most restrictive pressure relief requirement is used.

4. Emergency boration using the HPI system is assumed to be required for control of reactivity.

\section{Special Initiators}

Special initiators are modeled based on plant-specific considerations and as discussed earlier, focuses on initiators that causes plant trip and degrades the mitigation capability. Special initiators are typically transients with degraded mitigation capability. In some cases, SLOCAs may result. Special initiators are modeled similar to transients or combinations of SLOCA and transient, as applicable, taking into consideration the limitation in the mitigation capability due to the initiator. We specifically discuss the loss of seal cooling (LOSC) since it involves additional considerations. LOOP with loss of an emergency AC bus (LEAC) may be modeled for B\&W plants to account for the higher likelihood of SORV.

\section{Loss of Seal Cooling (LOSC)}

For the B\&W plants, seal cooling may be provided by different systems, e.g., Intermediate Cooling Water (ICW) or Nuclear Service Closed Cycle Cooling (NSCCC). The discussion here relates to loss of such systems where seal cooling is lost.

B\&W plants may be associated with Sultzer or BJ N-9000 seals. Considerations involved for modeling loss of seal cooling for these types of seals are discussed respectively under the $\mathrm{W}$ and $\mathrm{CE}$ plants. Please refer to the respective sections for the considerations that apply. 


\subsection{Pressurized Water Reactors: Combustion Engineering (CE) Plants}

\section{Transients (TRANS)}

The transient events include those events which result in reactor trip followed by failure to bring the reactor to safe shutdown. The sequences primarily involve failure to remove decay heat either by steam generator cooling or by primary system feed and bleed cooling. Some CE plants do not have PORVs (or alternate relief valves) and cannot use feed and bleed cooling.

1. Following a reactor trip, MFW usually does not isolate. Some CE plants have the ability to depressurize the secondary using steam generators and utilize condensate pumps for heat removal whenever all feedwater (main and auxiliary) is lost. Whenever applicable, this option for heat removal is credited. Multiple redundancies consisting of ADVs and MSSVs are available for the steam relief path. Considering the operator action for maintaining the feedwater flow and, as applicable, operator action for SG depressurization and use of condensate pumps, the PCS function is modeled with an operator action.

2. Some CE plants have alternate AFW/EFW pumps that may require manual actions. This could include crosstie to the other unit's AFW/EFW. These pumps are credited with applicable operator action considering the time requirement and common cause failure concerns.

3. The feed and bleed function varies significantly among CE plants. As mentioned above, some plants do not have feed and bleed capability. Some plants require both the available PORVs (because of their smaller size) for successful feed and bleed operation. Some plants have unique bleed designs. These specific capabilities and the associated operator action is used to define the feed and bleed or once through cooling function.

4. The HPR, i.e., switchover of the high pressure safety injection (HPSI) to sump following depletion of the Refueling Water Tank (RWT), is controlled by the Recirculation Actuation Signal (RAS) and is automatic.

5. At CE plants, since HPSI pumps directly take suction from the sump, the sump cooling is provided by the containment heat removal (CHR)systems. CHR can be carried out by the containment air coolers or containment spray pumps. The spray pumps take suction from the sump and are auto-aligned by the RAS. Containment air coolers are credited based on plant-specific PRA analyses.

\section{Transients With Loss of Power Conversion System (TPCS)}

These transients involve loss of the PCS that results in the reactor and turbine trip, e.g., loss of feedwater, loss of condenser vacuum, and loss of support systems leading to loss of the PCS. Here, recovery of feedwater or depressurization to use the condensate is not credited. The modeling considerations are the same as those of TRANS without any credit for PCS. 
In this initiating event, since PCS is not available, the steam relief path is included as part of the available AFW/EFW function. Usually highly redundant equipment consisting of MSSVs and $\mathrm{ADVs}$ is available.

\section{Small LOCA (SLOCA)}

An SLOCA includes break sizes where normal makeup through charging is not sufficient to maintain RCS inventory. An SLOCA will lead to reactor trip and the continued decrease in RCS pressure will lead to automatic actuation of the HPI system to maintain RCS inventory. The considerations in SLOCA modeling are as follows:

1. If the SG cooling is available, RCS inventory is maintained by HPI and long term cooling is provided by HPR and CHR which are initiated by RAS prior to RWT depletion. With the HPI available, RCS may be depressurized and long term cooling may be provided by shutdown cooling. However, in the SDP modeling, recirculation is required and termination of the event with transition to shutdown cooling is not credited. This modeling approach can be considered conservative.

2. MFW pumps and bypass valves are expected to be isolated in an SI signal. Recovery of motor-driven feed pumps and opening of the bypass valves are credited. Plants with a capability for secondary depressurization and use of condensate for heat removal can also use this option.

3. If adequate feedwater was not available and the feed and bleed option is available for the plant, then feed and bleed cooling could be accomplished through a pressurizer relief path and HPI/HPR can provide the core cooling.

4. In an SLOCA if HPI is not available, operators may be able to depressurize and use safety injection tanks (SITs) and low pressure safety injection (LPSI) for core cooling. If plantspecific PRA analyses justify such a strategy, then it is considered with applicable operator action credit. A requirement may include aggressive depressurization and cooldown with both the SGs in a relatively short time. Usually this strategy is not credited for CE plants, except for Palo Verde, a system $80 \mathrm{CE}$ plant.

\section{Stuck-Open Relief Valve (SORV)}

The intent of the SORV worksheet is to address the loss of RCS integrity condition as part of different initiators due to opening of and subsequently failing to reclose relief valves. As discussed above, CE plants have significant variations in the way relief valves are designed. Some plants have both PORVs and SRVs. Some others do not have PORVs; pressurizer relief may be through SRVs. In the CE plants, PORV is expected to be challenged only in selected transients. These transients are usually associated with loss of steam relief to condenser, e.g., loss of condenser vacuum. SRVs are not expected to be challenged or, in other words, the likelihood of stuck-open SRV after a transient is very small. Considering this, for plants with PORVs, stuck-open PORV is modeled as SORV. Since the PORV can be challenged in selected transients, considering the likelihood of such transients and the likelihood of the valve failing to close, the frequency of such initiators for $\mathrm{CE}$ 
plants is considered low. This initiator is placed in Row IV of Table 1 for CE plants. The considerations in modeling SORV are as follows:

1. Timely closure of the associated block valve is assumed to result in an event similar to the transient initiator. Additional modeling of the event, following closure of the block valve, was not necessary.

2. On failure to close the block valve, the initiating event is similar to SLOCA, and SLOCA modeling considerations apply.

3. Since a loss of feedwater event or a loss of offsite power may be the initiator that resulted in the SORV, PCS is usually not credited in this event.

\section{Medium LOCA (MLOCA)}

In an MLOCA, the flow is sufficient to remove decay heat (i.e., heat removal via SG is not needed), but makeup from HPI would be required to avoid core uncovery.

1. In an MLOCA, failure of HPI is assumed to lead to a core damage. RCSDEP for LPI is not credited because of the limited available time.

2. In the longer term, cooling is provided by HPR and CHR. HPR and CHR are auto actuated by RAS.

3. The need for SITs is based on plant-specific PRA analyses. For the Palo Verde plant, SITs are assumed to keep the core covered until HPI is initiated. One of the SITs is assumed to be lost through the break.

\section{Large LOCA (LLOCA)}

An LLOCA is characterized by rapid primary depressurization. As the RCS pressure is dropped, SITs will inject followed by LPI injection. Long term cooling is provided by HPR and CHR.

1. Success of SITs is assumed necessary in a LLOCA. SITs provide the early injection source needed to cool the core. One of the SITs is assumed to be lost through the break.

2. Following success of SITs, LPI is needed to maintain water in the vessel and failure of LPI leads to core damage.

3. Longer term cooling is provided by HPR and CHR. RAS switches the suction of HPSI and CS pumps to the containment sump.

4. Hot leg recirculation requirement is defined based on plant-specific PRA analyses. Hot leg recirculation may be required to prevent boron precipitation in the vessel. 


\section{Loss of Offsite Power (LOOP)}

A LOOP places a demand on the emergency power sources to start and to supply the loads necessary for establishing stable shutdown conditions. A LOOP creates special conditions on the availability of the systems required to maintain RCS integrity and core decay heat removal. Considerations in modeling the LOOP initiator involve addressing the special conditions, e.g., emergency power availability including alternate $\mathrm{AC}$, recovery of offsite power, $\mathrm{RCP}$ seal cooling requirement and seal LOCA considerations, and SBO coping capability.

1. Following early successful operation of emergency AC in a LOOP, the event progression is similar to a transient with a loss of power conversion system (TPCS). The RCPs are tripped due to the loss of $\mathrm{AC}$ power and the seal cooling is provided by the $\mathrm{CCW}$ or other cooling sources supported by emergency power.

2. In an SBO condition with availability of emergency feedwater sources not dependent on AC power, if alternate sources of seal cooling are not available, the possibility of seal LOCA is considered based on the type of the RCP seals.

In an SBO condition where RCPs have tripped and seal cooling is not available, operators are expected to isolate the bleed-off line averting a seal LOCA. It is modeled under the heading SEAL which includes operator failure to isolate the bleed-off line and the likelihood that seal LOCA will occur.

For BJ improved N-9000 design, the likelihood of seal failure with the failure to close the bleed-off line is low. For no seal cooling up to 4 hours, the likelihood of seal failure is of the order of $1 \mathrm{E}-4$, and for no seal cooling beyond 4 hours, it is of the order of $1 \mathrm{E}-3$. Considering the likelihood of operator failure to close the bleed-off line, the SEAL function is credited as 5 for no seal cooling up to 4 hours and as 4 for no seal cooling beyond 4 hours. Considering these low likelihoods coupled with likelihood of SBO conditions, the resulting sequences may be of low significance and may not be modeled.

For BJ Sultzer seals as in the Fort Calhoun plant (i.e., without the improved N-9000 design), the SEAL function is modeled with a credit of 2 considering a likelihood of seal failure of the order of 1E-1 given failure to close the bleed-off line. The operator action to close the bleed-off line is assigned a credit of 1 .

For improved 3 stage seals, as in the Palo Verde plant, seal cooling cannot be restored after loss of seal cooling for more than 30 minutes. Considering a higher likelihood of seal failure on failure to close the bleed-off line, SEAL is credited as 3.

3. In an $\mathrm{SBO}$ condition, non-AC dependent emergency feedwater sources (turbine-driven or diesel-driven emergency feedwater pumps) can successfully terminate the accident, if seal LOCA does not occur. However, continued operation of these pumps may be limited by the unavailability of instrumentation due to loss of battery. Recovery of offsite power or alternate sources to assure the availability of instrumentation is modeled as applicable. The time to 
recover offsite power may also be determined by seal LOCA, if that is assumed to occur, or other plant-specific considerations that may apply.

4. In an SBO condition with non-AC dependent EFW sources not available, recovery of offsite power is needed within a short time, 1 to 2 hours, to avert core damage. Without the recovery, SG dry-out will be followed by a core damage.

5. Following recovery of offsite power after SG dry-out has occurred, i.e., in an SBO condition with non-AC dependent EFW sources unavailable, recovered EFW/AFW is credited. SGs for CE plants are assumed to maintain their integrity with feedwater flow following the dry-

out. Feed and bleed cooling is assumed to be required, when available at the plant, if the EFW/AFW fails to operate.

\section{Steam Generator Tube Rupture (SGTR)}

SGTR can be considered a special case of SLOCA with the important difference being that RCS inventory enters the secondary and bypasses the containment. In such situations, the main strategy is to cooldown and depressurize the RCS below the affected steam generator MSSV setpoint so that leakage from primary to secondary is terminated and long term cooling can be achieved. Also, if the SG isolation does not occur (e.g., due to failure of a MSSV to close), then because of continuous inventory loss through the steam generator, inventory in the RWT may not be adequate for long term cooling by recirculation. RWT makeup will be required. The consideration in modeling SGTR for CE plants can be summarized below.

1. The event is assumed to reach a stable condition with successful SHR and HPI if the affected SG has been isolated and the primary to secondary leakage has been terminated through pressure equalization. Failure to isolate the affected $\mathrm{SG}$ and equalize pressure will require either providing makeup to the RWT or establishing shutdown cooling (SDC). Makeup to RWT is credited based on plant-specific PRA analyses.

2. On failure of HPI with SHR available, operators will need to depressurize the RCS and establish shutdown cooling. In other words, successful isolation of the affected SG and pressure equalization is followed by initiation of shutdown cooling. Charging pumps are required to continue to operate to provide inventory makeup.

3. When the faulted SG is isolated, with HPI available but SHR is failed, feed and bleed cooling with the PORV and long-term cooling using HPR and CHR can be accomplished.

4. MFW pumps are expected to be isolated on SI signal. They can be recovered for SHR. Recovery of motor-driven main feed pumps are credited based on plant-specific PRA analyses. Steam-driven main feed pumps are not credited.

\section{Main Steam Line Break (MSLB)}

MSLBs introduce overcooling to the RCS. Severity of the overcooling may result in a PTS to the vessel. Plant-specific PRAs usually do not consider the PTS, but in the SDP notebook PTS is 
considered making the modeling different from plant-specific PRAs. In modeling the MSLB, considerations used in addressing the PTS issues are as follows:

1. Closure of all the MSIVs will terminate the event similar to a transient with a loss of the PCS (TPCS).

2. Failure of two steam paths (MSIVs) to isolate is assumed to lead to core damage due to PTS.

3. In a situation where one of the steam path (MSIVs) has failed to close, operator action may be needed to terminate or throttle the HPI and to isolate feedwater.

4. In a situation where one of steam paths (MSIVs) has failed to close and HPI is unavailable, termination of feedwater to the SG whose MSIV didn't close is conservatively assumed to be needed.

5. Main feedwater is conservatively assumed to be unavailable due to the impact of this transient on the secondary side of the plant.

\section{Anticipated Transients Without Scram (ATWS)}

Transient with failure to trip the reactor is modeled separately in the notebook without modeling as part of each initiator. Loss of MFW was assumed to be a limiting situation for ATWS and therefore, ATWS is modeled considering loss of MFW as the transient where the reactor failed to trip. ATWS is only modeled for the conditions where the moderator temperature feedback is favorable. When moderator temperature feedback is unfavorable, core damage is assumed to occur, i.e., mitigation capability does not apply. Inspection findings relating to the mitigation capabilities that apply in ATWS when moderator temperature feedback is favorable is assessed with slightly conservative risk significance because of this approach. In other words, the implicit assumption is that moderator temperature feedback is favorable at all times giving the equipment and actions in the mitigation capability higher risk significance.

1. Operator action is credited for turbine trip if turbine trip did not occur as part of the transient.

2. SHR through the EFW is modeled considering auto-actuation of the EFW pumps. Emergency or auxiliary feed pumps requiring manual actions are not credited considering the limited time available. Steam relief requirements in ATWS may be more restrictive compared to transients, and such requirements are explicitly considered.

3. Primary pressure relief requirements can vary depending on the time in the fuel cycle when the event occurred. A conservative approach is used when the most restrictive pressure relief requirement is used.

4. Emergency boration using the charging and the boric acid makeup pumps from the boric acid tank is assumed to be required for control of reactivity. 


\section{Special Initiators}

Special initiators are modeled based on plant-specific considerations and, as discussed earlier, focus on initiators that cause plant trip and degrade the mitigation capability. Special initiators are typically transients with degraded mitigation capability. In some cases, SLOCA due to RCP seal failure may result. Special initiators are modeled similar to transients or combinations of SLOCA and transient, as applicable, taking into consideration the limitation in the mitigation capability due to the initiator. We specifically discuss the loss of seal cooling (LOSC) since it involves additional considerations. LOOP with loss of an emergency AC bus (LEAC) is not considered for CE plants since the likelihood of a PORV being challenged, for plants with a PORV, is lower making contribution of this initiator negligible.

\section{Loss of Seal Cooling (LOSC)}

For the CE plants, seal cooling is provided by CCW and in case of the Palo Verde plants, it is provided by Nuclear Cooling Water which is cooled by Plant Cooling Water. The discussion here relates to the initiators like Loss of CCW or Loss of Nuclear Cooling Water where seal cooling is lost.

RCP trip is questioned to prevent catastrophic seal failure. Operators are expected to isolate the bleed-off line averting a seal LOCA. It is modeled under the heading SEAL which includes operator failure to isolate the bleed-off line and the likelihood that seal LOCA will occur.

For BJ improved N-9000 design, the likelihood of seal failure with the failure to close the bleed-off line is low. For no seal cooling up to 4 hours, the likelihood of seal failure is of the order of $1 \mathrm{E}-4$, and for no seal cooling beyond 4 hours, it is of the order of 1E-3. Considering the likelihood of operator failure to close the bleed-off line, the SEAL function is credited as 5 for no seal cooling up to 4 hours and as 4 for no seal cooling beyond 4 hours. Considering these low likelihoods coupled with likelihood of SBO conditions, the resulting sequences may be of low significance and may not be modeled.

For BJ Sultzer seals, as in the Fort Calhoun plant (i.e., without the improved design), the SEAL function is modeled with a credit of 2 considering a likelihood of seal failure of the order of $1 \mathrm{E}-1$ given failure to close the bleed-off line. The operator action to close the bleedoff line is assigned a credit of 1 .

For improved 3 stage seals, as in the Palo Verde plant, seal cooling cannot be restored after loss of seal cooling for more than 30 minutes. Considering a higher likelihood of seal failure on failure to close the bleed-off line, SEAL is credited as 3.

\subsection{Pressurized Water Reactors: Westinghouse (W) Plants}

Different designs of Westinghouse (W) plants based on the number of loops and containment design have many commonalities and differences which influenced modeling assumptions. We present the discussions primarily considering W 2- loop and 4-loop plants, with additional considerations for 
other designs added, as applicable. Specific design characteristics applicable to only a small number of plants may not be covered.

\section{Transients (TRANS)}

The transient events include those events which result in reactor trip followed by failure to bring the reactor to safe shutdown. The sequences primarily involve failure to remove decay heat either by steam generator cooling or by primary system feed and bleed cooling.

1. Following a reactor trip, the MFW pumps will usually trip or runback. However, if AFW fails, operators can restore MFW. This requires operation of a condensate pump and a MFW pump. Multiple redundancies consisting of ADVs and MSSVs are available for the steam relief path. Considering the operator action for restoring the feedwater flow, the PCS function is modeled with an operator action.

2. W plants usually have motor-driven and turbine-driven or diesel-driven AFW pumps. In addition, some plants have additional AFW pumps, e.g., standby AFW pump, or can crosstie the other unit's AFW. Operator action is usually required for these additional AFW sources.

3. On loss of secondary cooling, operators are instructed to initiate feed and bleed cooling. Operators will start a high pressure pump and establish a bleed path opening the PORVs. The plants usually operate with primary block valves open. Operator action needed to conduct feed and bleed operation is modeled as part of the bleed operation, i.e., with opening the PORVs, and the HPI is modeled separately as automatic actuation. This way of treating the HPI allows use of similar HPI functions across the initiators. This approach makes the use of the notebook for evaluation easier.

4. High pressure recirculation (HPR), i.e., switchover of the HPI pumps to sump following depletion of Refueling Water Storage Tank (RWST), is needed for long term cooling. A low pressure train is aligned to take suction from the containment sump and discharge to the suction of HPI pumps via the residual heat removal heat exchanger. CCW is aligned for the heat exchanger. For some plants this switchover function is automatic. If not, this function is modeled as an operator action considering the applicable actions involved in the switchover.

5. On failure of high pressure recirculation, RWST makeup can be provided to continue HPI to provide core cooling and prevent core damage. Based on plant-specific PRA analyses and availability of procedures, this strategy is credited.

6. For large dry containment, containment cooling is assumed not required for preventing core damage.

\section{Transients With Loss of Power Conversion System (TPCS)}

These transients involve loss of the PCS that results in the reactor and turbine trip, e.g, loss of feedwater, loss of condenser vacuum, and loss of support systems leading to loss of the PCS. Here, 
recovery of feedwater or depressurization to use the condensate is not credited. The modeling considerations are the same as those of TRANS without any credit for PCS.

In this initiating event, since PCS is not available, the steam relief path is included as part of the available AFW function. Usually significant redundant equipment consisting of MSSVs and ADVs is available for this path.

\section{Small LOCA (SLOCA)}

An SLOCA includes break sizes where normal makeup through charging is not sufficient to maintain RCS inventory and, at the same time, full removal of decay heat cannot be achieved. An SLOCA will lead to reactor trip and the continued decrease in RCS pressure will lead to automatic actuation of the HPI system to maintain RCS inventory. The considerations in SLOCA modeling are as follows:

1. If the SG cooling is available, RCS inventory is maintained by HPI and long term cooling is provided by HPR following switchover to the recirculation mode. With the HPI available, RCS may be depressurized and long term cooling may be provided by low pressure recirculation (LPR) using the LPI pumps. Some PRA analyses model transition to the shutdown cooling mode following RCS depressurization with the consideration that loss of inventory is minimized and recirculation is not necessary. However, in the SDP modeling, recirculation is required and termination of the event with transition to shutdown cooling is not credited. This modeling approach can be considered conservative.

2. MFW pumps are expected to be isolated on an SI signal. Operators can recover motor-driven feed and condensate pumps. In some cases, operators can depressurize a SG to establish secondary flow through the condensate system. This action can be time consuming and is not separately credited in the notebooks.

3. If adequate feedwater was not available, then feed and bleed cooling could be accomplished through a pressurizer relief path and HPI. Longer term cooling is provided by HPR.

4. In an SLOCA, for some plants, failure of HPI will lead to core damage. For many others, operators can depressurize and use accumulators (ACCs) and LPI for core cooling. For some, accumulators may not be needed. This involves rapid cooldown and depressurization for LPI to avoid core uncovery. Longer term cooling is provided by LPR.

5. In case of failure of HPR, RWST refill can be credited based on plant-specific PRA analyses and availability of procedures.

\section{Stuck-Open PORV (SORV)}

The intent of the SORV worksheet is to address the loss of the RCS integrity condition as part of different initiators due to opening of and subsequently failing to reclose PORVs. There is a likelihood of a PORV being challenged as part of different initiators. The likelihood of SORV is defined considering the likelihood of PORV being challenged and the likelihood of PORV failing 
to reclose. For W plants, the initiating frequency of SORV is of the order of $1 \mathrm{E}-3$ and is placed in Row III of Table 1 in the notebook.

1. Early closing of the associated block valve is assumed to continue progression of the event similar to the transient initiator where the situation occurred. Additional modeling of the event, following closure of the block valve, was not necessary.

2. On failure to close the block valve, the initiating event is similar to SLOCA and SLOCA modeling considerations apply.

3. Since a loss of feedwater event or a loss of offsite power may be the initiator that resulted in the SORV, PCS is usually not credited in this event.

\section{Medium LOCA (MLOCA)}

In an MLOCA, the flow through the break is sufficient to remove decay heat (i.e., heat removal via SG is not needed), but makeup from HPI would be required to avoid core uncovery.

1. In an MLOCA, failure of HPI is assumed to lead to a core damage. RCSDEP for LPI is not credited because of the limited available time.

2. In the longer term, cooling is provided by HPR. RWST refill is usually not credited here considering the refill needs and time available.

\section{Large LOCA (LLOCA)}

An LLOCA is characterized by rapid primary depressurization. As the RCS pressure is dropped, ACCs will inject followed by LPI. Long term cooling is provided by LPR.

1. Success of ACC is assumed necessary in an LLOCA. ACCs provide the early injection source needed to cool the core. One of the ACCs is assumed to be lost through the break.

2. Following success of ACC, LPI is needed to maintain water level in the vessel and failure of LPI leads to core damage.

3. Longer term cooling is provided by LPR. For some plants, switchover of the suction of the LPI pumps to the containment sump is automatic. Otherwise, operator action is needed.

4. Hot leg recirculation requirement is defined based on plant-specific PRA analyses. Hot leg recirculation may be required to prevent boron precipitation in the vessel.

\section{Loss of Offsite Power (LOOP)}

A LOOP places a demand on the emergency power source to start and to supply the loads necessary for establishing stable shutdown conditions. A LOOP creates special conditions on the availability 
of the systems required to maintain RCS integrity and core decay heat removal. Considerations in modeling the LOOP initiator involve addressing the special conditions, e.g., emergency power availability including alternate $\mathrm{AC}$, recovery of offsite power, $\mathrm{RCP}$ seal cooling requirement and seal LOCA considerations, and SBO coping capability.

1. Following successful early operation of emergency AC in a LOOP, the event progression is similar to a transient with a loss of PCS (TPCS). The RCPs are tripped due to the loss of the $\mathrm{AC}$ power, and the RCP seal cooling is provided by the $\mathrm{CCW}$ or other cooling sources supported by emergency power.

2. In an SBO condition with the availability of EFW sources not dependent on AC power, if alternate sources of seal cooling is not available, the possibility of seal LOCA is considered based on the type of the RCP seals.

W plants are associated with two types of seals: "old" O-ring and high temperature O-ring seals. In the "old" O-ring seals, the likelihood of seal LOCA without seal cooling is approximately 0.2 within 13 minutes to 2 hours and close to 1 beyond 2 hours. For the high temperature O-ring seals, the likelihood of seal LOCA without seal cooling remains approximately 0.2 following the first 13 minutes (based on NRC Staff SER on WOG-2000 RCP Seal Model, 2003). However, if the seals survive the first 13 minutes, they are assumed to remain intact for the remainder of the transient. In the SDP notebook, the likelihood of seal LOCA is modeled with the SEAL function whose credit is determined considering the above likelihoods.

For the "old" O-ring seals, a credit of 1 is assigned for the SEAL function for the first hour, i.e., the likelihood of seal failure is considered following failure of the emergency diesel generators. When recovery of offsite power is considered within 1 to 2 hours, seal LOCA is likely to have occurred with a probability of 0.1 . For times beyond 2 hours, it is assumed that seal LOCA has occurred.

For the high temperature O-ring seals, seal LOCA with a probability of 0.1 is assumed for all time periods. In other words, the SEAL function is modeled following failure of emergency diesel generators with a credit of 1 .

3. Alternate $\mathrm{AC}$ requiring operator action takes 13 minutes or longer. Based on the above seal LOCA considerations, for both "old" O-ring and high temperature O-ring seal, seal LOCA can occur with a likelihood of 0.1 before alternate $\mathrm{AC}$ is available. Alternate $\mathrm{AC}$ is modeled along with recovery within 1 hour considering the likelihood of seal LOCA.

4. In an SBO condition, non-AC dependent emergency feedwater sources (turbine-driven or diesel-driven emergency feedwater pumps) can successfully terminate the accident, if seal LOCA does not occur. However, continued operation of these pumps may be limited by the unavailability of instrumentation due to loss of battery. Recovery of offsite power or alternate sources to assure the availability of instrumentation is modeled as applicable. The time to recover offsite power may also be determined by seal LOCA, if that is assumed to occur, or other plant-specific considerations that may apply. 
5. In an SBO condition with non-AC dependent EFW sources not available, recovery of offsite power is needed within a short time, 1 to 2 hours, to avert core damage. Without the recovery, SG dry-out will be followed by a core damage.

6. Following recovery of offsite power after SG dry-out occurred, i.e., in an SBO condition with non-AC dependent EFW sources unavailable, recovered EFW/AFW can be credited based on plant-specific analysis. Otherwise, feed and bleed cooling is assumed to be required.

7. RWST makeup may be credited to continue HPI cooling when HPR is not available. Such makeup is credited following recovery of offsite power since these sources usually depend on non-emergency power.

\section{Steam Generator Tube Rupture (SGTR)}

SGTR can be considered a special case of SLOCA with the important difference being that RCS inventory enters the secondary and bypasses the containment. In such situations, the main strategy is to cooldown and depressurize the RCS below the affected steam generator MSSV setpoint so that leakage from primary to secondary is terminated and long term cooling can be achieved. Also, if the SG isolation does not occur (e.g., due to failure of a MSSV to close), then because of continuous inventory loss through the steam generator, inventory in the RWST may not be adequate for long term cooling by recirculation. RWST makeup will be required. The consideration in modeling SGTR for W plants can be summarized below.

1. The event is assumed to reach a stable condition with successful SHR and HPI if the affected SG has been isolated and the primary to secondary leakage has been terminated through pressure equalization. Failure to isolate the affected SG and equalize pressure will require either providing makeup to the RWST or establishing SDC. Makeup to RWST is credited based on plant-specific PRA analyses.

2. On failure of HPI with SHR available, operators will need to depressurize the RCS and establish shutdown cooling. In other words, successful isolation of the affected SG and pressure equalization is followed by initiation of shutdown cooling. Charging pumps are required to continue to operate to provide inventory makeup.

3. When the faulted SG is isolated, with HPI available, feed and bleed cooling with the PORV and long-term cooling using HPR can be accomplished if the secondary heat removal is lost.

4. MFW pumps are expected to be isolated on an SI signal. They can be recovered for SHR. Recovery of motor-driven main feed pumps is credited based on plant-specific PRA analyses.

\section{Main Steam Line Break (MSLB)}

MSLBs introduce overcooling to the RCS. Severity of the overcooling may result in a PTS to the vessel. Plant-specific PRAs usually do not consider the PTS, but in the SDP notebook PTS is 
considered making the modeling different from plant-specific PRAs. In modeling the MSLB, considerations used in addressing the PTS issues are as follows:

1. Closure of all the MSIVs will terminate the event similar to a transient with a loss of the PCS (TPCS). For plants with higher pressure high head pumps, termination or throttling of the HPI may be needed to prevent forced opening of the PORVs.

2. Failure of two or more steam paths (MSIVs) to isolate is assumed to lead to core damage due to PTS.

3. In a situation where one of the steam paths (MSIVs) has failed to close, operator action is considered needed to terminate or throttle the HPI and to isolate feedwater. With initiation of both HPI and AFW/EFW, failure to terminate at least one of them is assumed to lead to core damage.

4. In a situation where one of the steam paths (MSIVs) has failed to close and HPI is unavailable, termination of feedwater to the SG whose MSIV did not close is conservatively assumed to be needed.

5. Following successful initiation of HPI and EFW for the plants with higher pressure high head pumps, operator action is needed to terminate or throttle high head injection. Failure of an operator to take this action will result in forced opening of the PORV(s) requiring HPR. This situation applies both when one or none of the MSIVs has failed to close.

6. MFW is conservatively assumed to be unavailable due to the impact of this transient on the secondary side of the plant.

\section{Anticipated Transients Without Scram (ATWS)}

Transient with failure to trip the reactor is modeled separately in the notebook without modeling as part of each initiator. Loss of MFW was assumed to be a limiting situation for ATWS and therefore, ATWS is modeled considering loss of MFW as the transient where the reactor failed to trip. ATWS is only modeled for the conditions where the moderator temperature feedback is favorable. When moderator temperature feedback is unfavorable, core damage is assumed to occur, i.e., mitigation capability does not apply. Inspection findings relating to the mitigation capabilities that apply in ATWS when moderator temperature feedback is favorable is assessed with slightly conservative risk significance because of this approach. In other words, the implicit assumption is that moderator temperature feedback is favorable at all times giving the equipment and actions in the mitigation capability higher risk significance.

1. ATWS Mitigation System Actuation Circuitry (AMSAC) is credited to trip the turbine and initiate AFW.

2. SHR through the AFW is modeled considering auto-actuation of the AFW pumps. Auxiliary feed pumps requiring manual actions are not credited considering the limited time available. 
Steam relief requirements in ATWS may be more restrictive compared to transients and such requirements are explicitly considered.

3. Primary pressure relief requirements can vary depending on the time in fuel cycle when the event occurred. A conservative approach is used where the most restrictive pressure relief requirement is used.

4. Emergency boration using the charging or HPI pumps and the boric acid transfer pumps from the boric acid tank is assumed to be required for control of reactivity.

\section{Special Initiators}

Special initiators are modeled based on plant-specific considerations and as discussed earlier, focus on initiators that cause plant trip and degrade the mitigation capability. Special initiators are typically transients with degraded mitigation capability. In some cases, an SLOCA may result. Special initiators are modeled similar to transients or combinations or SLOCA and transient, as applicable, taking into consideration the limitation in the mitigation capability due to the initiator. We specifically discuss the loss of component cooling water (LCCW) and LOOP with loss of an emergency AC Bus (LEAC) since they involve additional considerations

\section{Loss of Component Cooling Water (LCCW)}

Upon LCCW, RCP motor cooling is lost which could result in overheating and failure of the bearing. Bearing failure, in turn, could cause the shaft to vibrate and thereby result in the potential for seal failure if the RCPs are not tripped.

For the "old" W O-ring seals, the following considerations are used:

1. Credit for alternate cooling for charging pumps for seal injection is considered if the action can occur in less than 13 minutes (note: time zero is the point where no RCP seal cooling occurs, i.e., no seal injection or thermal barrier cooling). With the successful operator action within 13 minutes, seal failure is not questioned. Because of the time consideration, the operator action credit is assumed to be 1 . If the action cannot be performed within 13 minutes, then seal integrity is questioned with a credit of 1 prior to crediting the action for alternate cooling to charging.

2. In the longer term, if the action for alternate cooling to charging has failed, seal LOCA is assumed with a probability of 1 .

3. RCP trip is questioned to prevent catastrophic seal failure. Failure to trip the RCPs is assumed to lead to SLOCA.

For the high temperature O-ring seals, the following considerations apply:

1. Similar to the "old" W O-ring seals, credit for alternate cooling for charging pumps for seal injection is considered if the action can occur in less than 13 minutes. With the successful 
operator action within 13 minutes, seal failure is not questioned. Because of the time consideration, the operator action credit is assumed to be 1 . If the action cannot be performed within 13 minutes, then seal integrity is questioned with a credit of 1 prior to crediting the action for alternate cooling to charging.

2. In the longer term, if the action for alternate cooling to charging has failed, seal LOCA is not assumed. Seal LOCA is considered if it had occurred when seal integrity was questioned. This aspect for high temperature O-ring seals is different compared to "old" O-ring seals.

3. RCP trip is questioned to prevent catastrophic seal failure. Failure to trip the RCPs is assumed to lead to SLOCA.

\section{Loss of Service Water (LOSW)}

In LOSW, alternate cooling for the RCP seals should be provided in less than 30 minutes as opposed to 13 minutes (which applies for LCCW). It is assumed thermal barrier cooling will be degraded but will be effective for seal cooling until CCW system heats up due to the LOSW. Considerations for LOSW are similar to those for LCCW with the requirement for successful action to establish alternate cooling except the time required is less than 30 minutes.

\section{LOOP with Loss of an Emergency AC Bus (LEAC)}

A special initiator called LEAC is included for many plants to address risk-significant sequences associated with failure of a PORV to re-close (i.e., SORV) after it is demanded in a LOOP. The SDP worksheet for LOOP does not include the sequences involving the failure of a PORV to re-close, and the LEAC worksheet is specifically designed to take into account the inability to close the block valve associated with the SORV due to loss of power from the associated emergency AC bus. The considerations involved in modeling LEAC are as follows.

1. If the PORVs re-close following LEAC, the sequences are not explicitly included since they are considered as part of the LOOP worksheet.

2. Failure of the PORV to re-close following LEAC is modeled similar to an SLOCA with reduction in mitigation capability due to the loss of the emergency $\mathrm{AC}$ bus along with the LOOP.

\subsection{Boiling Water Reactors: General Electric (GE) Plants}

Modeling of BWR plants is presented focusing on the BWR $/ 4$ plants. When modeling considerations for other types of BWR plants differ, they are also presented. Specific design characteristics applicable to small number of plants may not be discussed here.

\section{Transients (Reactor Trip) (TRANS)}

The transient worksheet addresses those events or malfunctions in the plant that result in a plant trip without any impact on the mitigation capability of the plant. However, the modeling of the transient 
event provides the basis for modeling other initiators in the notebook and helps understand the approach/assumptions in the SDP modeling.

1. The PCS including both the feed path (the feed and condensate pumps) and the steam path (steam line and relief to condenser) for decay heat removal is modeled for successful termination of a routine transient. This is the preferred path. Operator actions are needed to perform this function. In the SDP notebooks, for transients where PCS-feed is affected but PCS-steam is available (as may be applicable for special initiators), PCS steam is modeled as part of CHR.

2. In BWR 4 plants, in cases of failure of the feedwater injection, the HPI sources modeled are the HPCI and RCIC systems. Control rod drive (CRD) system pumps can provide HPI, but are usually assumed to require initial success of other HPI sources, i.e., HPCI or RCIC.

Some plants have conducted evaluations showing successful early injection using CRD pumps without the initial success of other HPI sources. Use of CRD pumps as an early injection source requires maximizing flow from $2 / 2$ CRD pumps and can be applicable for different transient and SORV scenarios. Such credit of CRD pumps should be reevaluated and may not be valid when power level is increased or uprated. SDP notebooks does not credit use of CRD pumps as an early HPI source similar to HPCI and RCIC. Use of CRD as a late injection ( $\mathrm{LI}$ ) is credited. In addition, survival of CRD pumps following containment failure is considered.

For BWR 5/6 plants, enhanced flow with $2 / 2$ CRD pumps as an early injection source is credited as these plants are designed with such capability.

3. In case of failure of the HPI sources, operator action to open the required number of SRVs is considered for depressurization and injection by automatic low pressure systems.

4. Following depressurization, automatic injection by LPI systems, namely residual heat removal (RHR) in low pressure coolant injection (LPCI) mode and Low Pressure Core Spray (LPCS), is considered. Common-cause failure of permissive instrumentations can result in failure of both the RHR and LPCS pumps limiting the redundancy available for low pressure systems. If the common-cause failure of such instrumentation is a dominant contributor, then it is modeled as a separate top event requiring success for operation of low pressure pumps. The modeling of permissive instrumentation is done on a plant-specific basis based on contribution of such failures.

5. CHR or suppression pool cooling (SPC) is carried out by the RHR system in the SPC or SDC mode. Operator action is needed for this action, but it is considered highly reliable and the credit is determined by the hardware failures.

6. Containment venting (CV) by the operator is credited in case of failure of SPC. Both the hardened and non-hardened vent paths are credited. For plants with pressure controlled venting, only hardened vent paths are credited. When pressure controlled venting is proceduralized and is credited, then continued injection by the LPI systems can be credited. 
When non-hardened vent paths are credited, then continued injection by the systems drawing from the suppression pool is assumed unsuccessful. Uncontrolled venting will compromise operation of emergency core cooling system (ECCS) pumps drawing from suppression pool due to loss of normal pump suction head (NPSH). Use of non-hardened vent path also has the potential to create a harsh environment in the reactor building. Only systems with suction sources outside of the reactor building can be considered for LI.

With successful pressure controlled venting, credit for continued operation of HPIC and RCIC depends on multiple factors. They include consideration of turbine trip on high exhaust pressure and temperature, availability of steam for long periods of time, availability of condensate storage tank makeup, and plant response to maximum primary containment level limit. Credit for continued operation of HPCI and RCIC is given if plant-specific PRA analyses are available considering the plant procedure and the factors discussed above.

7. LI to prevent core damage is credited following successful CV. Multiple systems may be available for injection. They include CRD system for high pressure injection or other low pressure systems following depressurization. Examples of low pressure systems include condensate pumps, condensate transfer pumps, fire pumps, and high pressure service water pumps through the RHR line. In case of pressure controlled venting with continued success of the injection systems (LPCI, LPCS, or HPCI/RCIC, as applicable), LI is not required. Successful pressure controlled venting will lead to successful termination of the event.

8. LI following failure of CV is usually limited. Resulting harsh environment following containment failure can affect injection paths. In such a scenario for transients and SLOCA initiating events, SRVs will likely close and primary will repressurize. In such conditions, LPI sources cannot be used, and only the HPI system with a source of water outside of the reactor building can be used. Usually, CRD is the only applicable HPI system that can be credited in these scenarios. The harshness of the condition following containment failure is modeled as a top event with a probability of 1E-1 and the CRD injection in a harsh environment is modeled separately with an operator action credit considering the harsh environment. In MLOCA and LLOCA conditions, the primary system cannot pressurize and low pressure systems can also be used for injection.

9. Plants with loop selection logic selects one of the loops for injection based on the pressure difference across the loops. To assure that injection flow is not lost through the broken loop, LPCI flow is aligned to the intact loop. This condition is modeled considering LPCI as a single train system with all LPCI pump flow aligned to this train. Selection of one loop may apply for all initiating events, i.e., even when none of the loops has ruptured. In other words, LPCI is modeled as a single train system with all LPCI pumps aligned to the train for all the initiating events considered for the plant.

10. For BWR 5/6 plants, the high pressure core spray (HPCS) system provides HPI. These pumps are motor-driven and are capable of pumping saturated water at atmospheric pressure. The operation of pump motors is not expected to be affected by steam and they are assumed to continue operation following failure of suppression pool cooling with successful venting. The ability of HPCS to continue operation following containment failure, i.e., with failure 
of CV following failure of SPC, is considered based on plant-specific PRA analyses. Because of the difference in capability in HPCS and RCIC, they are modeled under separate headings or top event.

11. For BWR $5 / 6$ plants, LPCI pumps have the capability to pump saturated water at atmospheric pressure. In case of SPC failure with successful CV, LPCI pumps can continue operation and alternate sources of injection are not needed. Similar to the HPCS pump, operation of LPCI pump is not affected by the steam released from CV.

\section{Transients Without Availability of Power Conversion System (TPCS)}

This initiating event considers a transient with the loss of the PCS and includes many types of initiating events that may be considered separately in a PRA of a plant. These initiating events typically include loss of feedwater, loss of condenser vacuum, loss of turbine building component cooling water, and MSIV closure. In this modeling, it is assumed that no part of the PCS is available for mitigating the transient.

The consideration for this modeling in the SDP notebook is similar to that of a transient discussed earlier without any credit for the PCS.

\section{Small LOCA (SLOCA)}

An SLOCA is characterized by slow or no reactor vessel depressurization and a gradual inventory loss from the vessel. RCIC makeup capability is considered sufficient to maintain adequate coolant inventory.

1. SLOCA will result in a reactor scram and a turbine trip. Higher drywell pressure will lead to loss of feedwater pumps, but operators can recover the feed pumps from the control room. The notebooks give credit for recovery of the feed pump. The operator action credit depends on whether the feed and condensate pumps are motor-driven or steam-driven. Higher credit is usually given for the motor-driven pumps.

2. Since SLOCA is characterized by a break where RCIC makeup capability is sufficient to maintain coolant inventory, both HPCI and RCIC are credited as HPI sources. Continued operation of CRD is not credited as a high pressure injection source without success of HPCI or RCIC.

3. In an SLOCA, following success of HPI (HPCI or RCIC), LPI sources are needed because HPI sources are steam-driven and, at some point, they will isolate on low steam pressure. However, by that time sufficient depressurization has taken place for LPI sources to supply water to the vessel.

4. Depressurization is needed in an SLOCA for injection by low pressure systems in case of failure of high pressure systems (i.e., HPCI and RCIC). Similar to transients, a required number of SRVs are opened by the operators. 
5. CHR, CV, and $\mathrm{LI}$ requirements are similar to transients.

\section{Medium LOCA (MLOCA)}

An MLOCA is characterized by slow vessel depressurization and gradual inventory loss from the vessel. These LOCA sizes are considered initially within the capacity of HPCI or HPCS, but not the RCIC system.

1. Early containment pressure control is accomplished through the vacuum breakers which can allow return flow of the non-condensed steam from torus/suppression pool to the drywell. Failure of the vacuum breakers to remain closed will result in high containment pressure. Drywell spray may be initiated to control pressure in case of vacuum breaker failure. For MLOCA, early containment pressure control is modeled, if it is judged applicable in plantspecific PRA analyses, considering successful closure of vacuum breakers or use of drywell spray. A required number of vacuum breakers to remain closed is determined based on plant-specific success criteria. Drywell spray will need to be initiated within a short time and is credited with applicable operator action based on plant-specific analysis.

2. HPCI or HPCS is credited for early injection followed by LPI due to depressurization from the break. Success of HPCI or HPCS provides early injection and additional depressurization of the primary system.

3. Failure of HPCI or HPCS requires depressurization opening the SRVs for injection by low pressure systems. Usually, a fewer number of SRVs compared to SLOCA will need to be opened by the operator.

4. LI considerations similar to those discussed for transients apply. In addition, LI may be limited due to inadequate capacity or time. CRD pumps are considered not to have enough capacity and, in many cases, fire pumps may not have sufficient capacity either. Condensate pumps, RHR service water (RHRSW) pumps are considered to have sufficient capacity, but the operator action credit may be limited because of the limitation in time.

5. Following containment failure, the reactor is not expected to repressurize and LPI sources may still be used. In a containment failure, injection lines may be affected, and considering the potential impact on the RHR/LPCI line, RHRSW which used the same path is not credited. Condensate pumps may be credited.

\section{Large LOCA (LLOCA)}

An LLOCA is characterized by rapid vessel depressurization and rapid inventory loss from the vessel. HPCI and/or RCIC do not have capacity to mitigate LLOCA and feedwater is unavailable due to expected closure of MSIV. Rapid depressurization is accomplished via flow out of the break. Low pressure coolant injection systems provide the necessary inventory makeup and core protection.

1. Early containment pressure control is accomplished through the vacuum breakers which can allow return flow of the non-condensed steam from torus/suppression pool to the drywell. 
Failure of the vacuum breakers to remain closed will result in high containment pressure. For LLOCA, early containment pressure control is modeled considering successful closure of vacuum breakers. A required number of vacuum breakers to remain closed is decided based on the plant-specific success criteria. A fewer number of vacuum breakers may be required to be remain closed, compared to MLOCA, because higher pressure in drywell may push some steam through the wetwell reducing the flow through the breakers.

2. LPI, CHR, and CV functions are modeled similar to those discussed earlier for other initiating events.

3. LI is limited because of the insufficient capacity and time for some injection sources. LI sources are modeled similar to MLOCA.

\section{Loss of Offsite Power (LOOP)}

With the LOOP, the PCS is unavailable because it is powered by the non-class $1 \mathrm{E}$ or non-safety buses. For plant response to this transient, AC power is provided by the EDGs and, in parallel, effort is made to recover offsite power. In case of failure of diesel generators, operator action is needed to align any alternate source of power, e.g., use of gas turbine, crosstie to the other unit.

1. For dual unit sites, a dual unit loss of offsite power is assumed. This assumption of dual unit LOOP may limit the credit for crosstie to the opposite unit's electrical power. In case of sites where EDGs are shared, the credit for EDGs needs to be defined considering the need for both the units in a LOOP.

2. Alternate AC power sources like SBO diesel generator, swing EDG, Gas Turbine generator, or crosstie to the other unit's EDG are credited similar to the dedicated EDGs when they can be aligned within approximately 30 minutes. The HEP of aligning these sources should be less than 0.5 and usually an operator action credit of 1 is assigned. Nearby power stations could also be affected by the underlying causes of the LOOP. They can be credited as recovery actions if they have underground cables and justification can be made that they will not be impacted by the LOOP.

3. Successful start of the required number of diesels or the alignment of the alternate AC source will allow progression and termination of the initiating event similar to a loss of PCS transient. In some cases, CV and LI sources depend on offsite power sources and their credit may be limited. CV may depend on instrument air without any backup ACCs and recovery of offsite power may be needed for CV. Since multiple sources are usually available for LI sources, only those supported by emergency power are credited.

4. Following failure of emergency power, i.e., in an SBO condition, HPI sources HPCI and RCIC can operate as long as the DC power depending on the battery capacity is available. Offsite power will need to be recovered within that time. In some cases, where battery life is long, HPCI and RCIC may be lost because of loss of ventilation which may determine the time for recovery of offsite power. The justification for the time for recovery of offsite power when HPI is functioning is noted in a footnote. 
5. In an SBO condition, if HPI fails, then recovery of offsite power may be needed in 1 hour or less. Specific timing of the recovery is determined from the plant-specific analysis or assumption. If the HEP for the recovery within the time period is high, i.e., greater than 0.5 , then such recovery is not credited.

6. For BWR $5 / 6$ plants, HPCS diesel is modeled with HPCS system, separate from the EDGs which are required to start and provide power following LOOP. A common-cause failure of the diesels including the HPCS-diesel may apply. In such cases, where failure of EDGs is considered along with HPCS, the credit of HPCS is adjusted to account for the commoncause failure of the diesels.

\section{Anticipated Transients Without Scram (ATWS)}

The ATWS model addresses such situations resulting from different initiating events. In the screening approach, a severe ATWS where MSIV s are closed and feedwater and PCS are unavailable is assumed. It is also assumed that ATWS is not recoverable by manual insertion of rods or through ARI. Systems and features that are effective in achieving reactor shutdown without the control rods are credited.

1. Overpressure protection is provided by the relief valves. Success criteria is based on the plant-specific analyses and the requirement presented in the plant PRA.

2. Failure to trip the recirculation pumps is assumed to lead to a core damage. Failure of the recirculation pumps to trip can primarily result from failure of the circuit breakers associated with the pump trip logic.

3. Standby liquid control (SLC) may be actuated manually even before the automatic actuation setpoint is triggered. The success criteria for SLC pumps depend on when SLC is actuated. If the action is needed to be completed within 3 minutes for a different success criteria, then, considering the high HEP for the short time involved, such action is not credited. The success criteria associated assuming failure of the action within the first 3 minutes are used.

4. The HPI source is usually HPCI or HPCS. Considering plant-specific analyses, RCIC may also be credited. Early HPCS/HPCI injection which may occur due to auto-actuation of HPCS/HPCI when the vessel level drop may result in spraying the core with relatively cold water early in the transient and should be avoided. Securing HPCS/HPCI is usually modeled as part of the inhibit function.

5. $\quad \mathrm{CHR}, \mathrm{CV}$, and $\mathrm{LI}$ requirements are similar to transients.

\section{Special Initiators}

Special initiators are modeled based on plant-specific considerations and as discussed earlier, focus on initiators that cause plant trip and degrade the mitigation capability. Special initiators are 
typically transients with degraded mitigation capability and are modeled similar to transients. Applicable considerations in modeling special initiators for BWRs are discussed below.

Loss of instrument air (LOIA) is typically modeled for BWRs even though the impact of the initiator is similar to a transient with loss of PCS. LOIA is usually an important contributor to plant CDF and findings associated with components with instrument air system are risk significant, i.e., with a color higher than green. Modeling LOIA allows for proper assessment of risk significance of findings associated with instrument air system.

Loss of DC buses are typically modeled as an initiator and loss of redundant buses are modeled separately because of the asymmetry of the impact. Usually one of the DC buses support the HPCI pump and the other bus supports the RCIC pump, requiring modeling each of the buses separately. In some cases, CV may be affected by the loss of the DC bus.

Loss of service water can be an important contributor as it may affect the SPC due to the loss of the RHR heat exchanger along with loss of the feed path of the PCS. Loss of service water is modeled considering such impacts on the mitigation capability. 


\section{APPLICÁBILITY OF THE SDP NOTEBOOKS}

SDP notebooks are designed to be a tool for screening and conducting a quick assessment. In that respect, they are not designed to provide detailed results and understanding that may be obtained from a detailed plant-specific PRA which includes detailed engineering analyses. The limitations/applicability of the tool can be summarized as follows:

1. SDP notebooks provide engineering understanding and risk significance of an inspection finding. Engineering understanding is provided considering the impact at the system train level and the risk significance is obtained within an order of magnitude. The tool is not designed to obtain results beyond that level and attempts to do that may not be desirable.

2. The notebook assumes knowledge about the plant systems and, in some cases, requires additional information for assessing significance of the inspection finding. To keep the focus of the notebook on the inspection assessment phase, the additional information that may be needed and can be gathered at the plant has not been included. In that respect, the notebooks are not completely self contained, but may require supplemental information.

3. In its attempt to develop a relatively simple process whereby inspection findings can be assessed quickly, approximations are made both in modeling plant responses and in assessing the risk significance. This results in overestimations and, in few cases, underestimations compared to the detailed plant-specific PRAs. These over and underestimations are noted in the notebooks and the reasons for these differences should be taken into consideration in using the results.

4. Overestimation of the risk significance by the notebook can result from multiple factors embedded in the way the notebooks are developed and used. Plant initiators and modeling of plant response may be conservative because of the simplifications and attempt to maintain similar characteristics across similar plants. Data used in the plant PRA may indicate better reliability of the equipment and human actions compared to the generic approach used by the notebooks in crediting these mitigation capabilities. Evaluation of the significance is particularly conservative when multiple redundancies remain available.

5. Underestimations are relatively few but can also result from several factors. Underestimation can result from modeling differences where one feature of the plant becomes more significant in the plant PRA compared to in the notebook. In some cases, equipment or human reliability may be slightly higher than that assumed in the notebook and combinations thereof may result in the underestimation. In addition, in some cases some unique dependencies which are difficult for the user to consider in the evaluation phase may also result in an underestimation.

6. Care should also be taken if multiple, independent failures, particularly in the support systems, are evaluated. Underestimations may occur because in the simplified approach used in the notebooks system interactions and dependencies involving multiple systems may be difficult to account for in the evaluation phase. Usage Rules for evaluating these multiple, independent failures are not developed and they may be more involved. 


\section{REFERENCES}

USNRC SECY-99-007A, Recommendations for Reactor Oversight Process Improvements (Followup to SECY-99-007), March 22, 1999.

Risk Inspection Notebook for Arkansas Nuclear One-Unit 1, Brookhaven National Laboratory, August 2003. (Notebooks are available for all operating US nuclear power plants; this reference is presented as an example.) 


\section{APPENDIX A}

\section{USAGE RULES}

\section{FOR SIGNIFICANCE DETERMINATION}

\section{OF REACTOR INSPECTION FINDINGS}

FOR AT-POWER SITUATIONS 


\section{TABLE OF CONTENTS}

Page

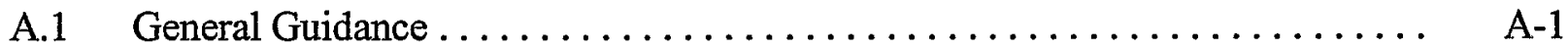

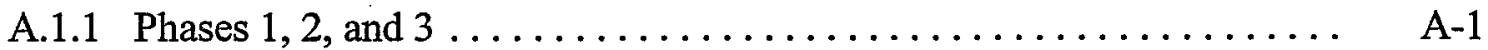

A.1.2 Use of SDP Phase 2 Worksheets $\ldots \ldots \ldots \ldots \ldots \ldots \ldots \ldots \ldots$ A-1

A.2 Site Specific Risk-Informed Inspection Notebook Usage Rules .......... A-2

A.2.1 Determining Initiating Event Likelihood and Impact on Mitigation

System Capability ................................ A-2

A.2.1.1 Exposure Time $\ldots \ldots \ldots \ldots \ldots \ldots \ldots \ldots \ldots \ldots \ldots \ldots \ldots \ldots \ldots$ A-2

A.2.1.2 Inspection Finding (Not Involving a Support System) that Increases the Likelihood of an Initiating Event $\ldots \ldots \ldots \ldots$ A-2

A.2.1.3 Inspection Finding (Normally Crosstied Support System) that Increases the Likelihood of an Initiating Event..$\ldots \ldots \ldots$

A.2.1.4 Inspection Finding (Normally Running Components of a Split Train Support System) When the Failure of One Train is an Initiating Event That Also Impacts the Mitigating System Capability Which Can Be Explicitly Determined ..........

A.2.1.5 Inspection Finding (Normally Standby Components of a Split Train Support System) When the Failure of One Train is an Initiating Event that Impacts the Mitigating System Capability Which Can Be Explicitly Determined .................

A.2.1.6 Inspection Finding of a Component in a Split Train Support System When the Failure of the Entire System is an Initiating Event and Could Impact the Mitigating System Capability Which Can Be Explicitly Determined .............. A-5

A.2.1.7 Inspection Findings Involving Emergency Diesel Generators . A-6

A.2.1.8 Inspection Findings Involving Safety-Related Battery Chargers .......................... A-7

A.2.1.9 Inspection Findings Involving Safety-Related Battery ...... A-8

A.2.2 Determining Remaining Mitigation Capability ............. A

A.2.2.1 Inspection Finding that Degrades Mitigation Capability But Does Not Reduce Remaining Mitigation Capability Credit to a Value Less Than Full Mitigation Credit ...............

A.2.2.2 Inspection Finding (Normally Split Train Support System) that Does Not Increase the Likelihood of an Initiating Event and the Impact on Mitigation System Capability Can Be Explicitly

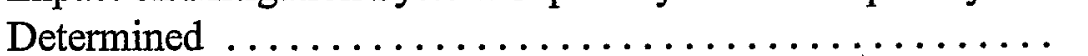

A.2.2.3 Inspection Findings Involving a Loss of Redundancy of Equipment..$\ldots \ldots \ldots \ldots \ldots \ldots \ldots \ldots \ldots \ldots \ldots \ldots$ 


\section{TABLE OF CONTENTS \\ (Continued)}

A.2.2.4 Inspection Findings Involving Equipment that Impact

Page

Operator Action Credit

A.2.3 Characterizing the Risk Significance of Inspection Findings $\ldots \ldots \ldots \ldots$ A-12

A.2.3.1 Treatment of Shared Systems Between Units . . . . . . . . . . A-12

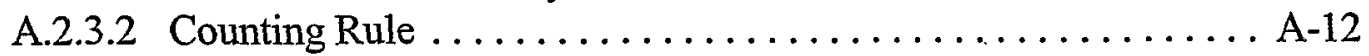




\section{A.1 General Guidance}

\section{A.1.1 Phases 1, 2, and 3}

The plant-specific reactor safety SDP uses a graduated three-phase process to differentiate inspection findings on the basis of their potential risk significance. The staff's final significance determination may be based on any of these three phases.

Phase 1 Characterization and Initial Screening of Findings:

Characterization of the finding and an initial screening of very low-significance findings for disposition by the licensee's corrective action program.

Phase 2 Risk Significance Estimation and Justification Using the Site Specific Risk-Informed Inspection Notebook:

Plant specific estimation of the risk significance of an inspection finding and development of the basis for the determination.

Phase 3 Risk Significance Estimation Using Any Risk Basis That Departs from the Phase 1 or 2 Process:

Any departure from the guidance provided in this Appendix for Phase 1 or Phase 2 constitutes a Phase 3 analysis. Phase 3 analysis methods will utilize appropriate PRA techniques and rely on the expertise of NRC risk analysts.

Phases 1 and 2 are intended to be accomplished by the inspection staff, with the assistance of a senior reactor analyst (SRA), where necessary. Phase 3 is intended to be performed by a SRA or risk analyst.

This appendix focuses on the Phase 2 assessment. Inspectors should obtain the licensee's risk perspectives as early in the SDP process as a licensee is prepared to offer them, and use the SDP framework to the extent possible to evaluate the adequacy of the licensee's assumptions.

\section{A.1.2 Use of SDP Phase 2 Worksheets}

The Phase 2 Worksheets are plant-specific to account for variations in available mitigation equipment and other plant-specific attributes. The Phase 2 Worksheets are included in the site specific risk-informed inspection notebook.

To enter the Phase 2 process, the staff should state the performance deficiency and factually describe the known observations associated with the issue; describe the assumed impact on affected plant safety functions; and should not include hypothetical conditions (e.g., single failure criteria). A A bounding determination of significance may be made by assuming a worst-case condition (e.g., assume complete loss of function for the component under evaluation, even if unsupported by the 
facts known at that time). If a bounding determination results in greater than green, greater factual detail will be necessary to complete the SDP.

Because the purpose of the SDP is to estimate the increase in core damage frequency due to deficient licensee performance, the SDP evaluation should not include equipment unavailability due to planned maintenance and testing. The impact of this equipment not being available for mitigation purposes is included in the baseline core damage frequency for each plant.

\section{A.2 Site Specific Risk-Informed Inspection Notebook Usage Rules}

\section{A.2.1 Determining Initiating Event Likelihood and Impact on Mitigation System Capability}

\section{A.2.1.1 Exposure Time}

The exposure time used in determining the Initiating Event Likelihood (IEL) should correspond to the time period that the condition being assessed is reasonably known to have existed. If the inception of the condition is unknown, then an exposure time of onehalf of the time period since the last successful demonstration of the component or function $(t / 2)$ should be used.

Basis:

A $t / 2$ exposure time is used when the inception of the condition being assessed is unknown because it represents the mean exposure time for a statistically valid large sample.

Example:

Consider an inspection finding that corresponds to the loss of a safety function which was identified as a result of a failed monthly surveillance. Also consider that the loss of safety function was not the result of a misalignment or human error that took place in the last maintenance or routine testing. Therefore, in this case, the inception of the condition is unknown. If the monthly surveillance was last successfully performed 32 days prior to the surveillance failure, an exposure time of 16 days for assessing the IEL in Table 1 of the SDP notebook (greater than 3 but less than 30 days) would be used in assessing the inspection finding.

A.2.1.2 Inspection Finding (Not Involving a Support System) that Increases the Likelihood of an Initiating Event

If the increase in the frequency of the initiating event due to the inspection finding is not known, increase the Initiating Event Likelihood (IEL) for the applicable initiating event by one order of magnitude. If specific information exists that indicates the IEL should be increased by more than one order of magnitude, consult with the regional Senior Reactor Analyst (SRA) to determine the appropriate IEL. 
Basis:

This simplified rule was needed to facilitate Phase 2 screening. Scaling up the frequency of an initiating event strongly depends on the type and the severity of the inspection finding. Judgment and experience with the use of the Phase 2 notebooks were used in defining this rule. If an increase by more than one order of magnitude is believed to be appropriate, the SRA should be consulted.

\section{Example:}

Consider an inspection finding that involves an error in a relay calibration procedure that results in the undervoltage setpoint on the supply breakers from each of the offsite power lines being set incorrectly high. As a result, normal voltage perturbations on the offsite power distribution system could result in a loss of offsite power (LOOP) event. The exposure time associated with this inspection finding is 10 days. Using Table 1 , "Categories of Initiating Events," an IEL of 3 would normally be obtained; but, because the inspection finding increases the likelihood of a LOOP event, an IEL of 2 would be applicable and should be used. Each of the sequences on the LOOP worksheet would then have to be solved because the LOOP initiating event frequency is a contributor in each of these sequences. For those plants that have a special initiator for LOOP with loss of one $\mathrm{AC}$ bus (LEAC), this worksheet would be solved in a similar manner.

\section{A.2.1.3 Inspection Finding (Normally Crosstied Support System) that Increases the Likelihood of an Initiating Event}

For inspection findings that involve the unavailability of one train of a multi-train, normally crosstied support system that increases the likelihood of an initiating event, increase the Initiating Event Likelihood (IEL) by one order of magnitude for the associated special initiator.

Basis:

Simple reliability models and generic data have been used to determine that an order of magnitude increase is appropriate for different configurations of crosstied support systems. For example, based on generic data the initiating event frequency for a crosstied support system with one running train and two standby trains is on the order of $1 \mathrm{E}-4$ per year. The initiating event frequency for a crosstied support system with one running train and one standby train is on the order of 1E-3 per year. Therefore, if an inspection finding causes the former system configuration to be changed to the latter, the risk significance should be evaluated by increasing the initiating event frequency by one order of magnitude.

\section{Example:}

Consider an inspection finding that involves the unavailability of one of three component cooling water pumps. Each of the pumps is capable of providing 100 percent of the required flow. The component cooling water (CCW) system is a two train system that is 
normally crosstied. The exposure time associated with this inspection finding is 90 days. The loss of CCW special initiator is located in Row III of Table 1, "Categories of Initiating Events," for the affected plant. As a result, an IEL of 3 would normally be assigned when solving loss of CCW accident sequences; but, because the inspection finding increases the likelihood of a loss of CCW event, an IEL of 2 would be used. Each of the sequences on the loss of CCW worksheet would then have to be solved because the loss of CCW initiating event frequency is a contributor in each of these sequences.

A.2.1.4 Inspection Finding (Normally Running Components of a Split Train Support System) When the Failure of One Train is an Initiating Event That Also Impacts the Mitigating System Capability Which Can Be Explicitly Determined

For inspection findings that involve the unavailability of a normally running component of a split train support system that increases the likelihood of an initiating event, increase the Initiating Event Likelihood (IEL) by one order of magnitude for the associated special initiator. In addition, determine the impact on the mitigation capability of the supported systems and evaluate each of the worksheets directed by Table 2, "Initiators and System Dependency," nominally for the affected systems.

Basis:

Simple reliability models and generic data have been used to estimate the failure probabilities of plant equipment. A generic failure probability for one normally running train is approximately $1 \mathrm{E}-1$ [(1E-5 per hour) $\mathrm{x}(8760$ hours) $\approx 1 \mathrm{E}-1]$. Therefore, it is appropriate to increase the IEL by one order of magnitude for inspection findings involving a normally running component of a split train support system.

\section{Example:}

Consider an inspection finding that involves the unavailability of a normally running pump in a component cooling water (CCW) system. The CCW system is a split, two train support system with one pump normally running in each train and with a swing pump in standby mode that can be aligned to either train. The supported mitigating systems that are impacted by the unavailability of one train of CCW are one of three trains of the high pressure safety injection (HPSI) and residual heat removal (RHR) systems. Loss of one train of the CCW system is also an initiator since it supports the cooling for two of the Reactor Coolant Pumps (RCPs). The exposure time associated with this inspection finding is 21 days. The loss of one train of CCW special initiator is located in Row III of Table 1, "Categories of Initiating Events," for the affected plant. As a result, an IEL of 4 would normally be assigned when solving loss of $\mathrm{CCW}$ accident sequences. But, because the finding pertains to a normally running CCW pump, an IEL of 3 would be used. In addition, each of the worksheets specified by Table 2, "Initiators and System Dependency," for the HPSI and RHR systems needs to be solved nominally. 
A.2.1.5 Inspection Finding (Normally Standby Components of a Split Train Support System) When the Failure of One Train Is an Initiating Event that Impacts the Mitigating System Capability Which Can Be Explicitly Determined

For inspection findings that involve the unavailability of a normally standby component of a split train support system that increases the likelihood of an initiating event, increase the Initiating Event Likelihood (IEL) (for the failure of the train) by two orders of magnitude for the associated special initiator. In addition, determine the impact on the mitigation capability of the supported systems and evaluate each of the worksheets directed by Table 2, "Initiators and System Dependency," nominally for the affected supported systems.

Basis:

Simple reliability models and generic data have been used to estimate the failure probabilities of plant equipment. A generic failure probability for a normally standby train is approximately $1 \mathrm{E}-2$. Therefore, it is appropriate to increase the IEL by two orders of magnitude for inspection findings involving normally standby components of split train support systems.

\section{Example:}

Consider an inspection finding that involves the unavailability of a standby pump in a component cooling water (CCW) system. The $\mathrm{CCW}$ system is a split, two train support system with one pump normally running in each train and with a swing pump in standby mode that can be aligned to each of the trains if necessary. The supported mitigating systems that are impacted by the unavailability of one train of CCW are one of three trains of the high pressure safety injection (HPSI) and residual heat removal (RHR) systems. Loss of one train of the CCW system is also an initiator since it supports the cooling for two of the reactor coolant pumps (RCPs). The exposure time associated with this inspection finding is 21 days. The loss of one train of CCW special initiator is located in Row III of Table 1, "Categories of Initiating Events," for the affected plant. As a result, an IEL of 4 would normally be assigned when solving loss of CCW accident sequences. But, because the finding pertains to a normally standby CCW pump, an IEL of 2 would be used. In addition, each of the worksheets specified by Table 2, "Initiators and System Dependency," for the HPSI and RHR systems need to be solved nominally.

A.2.1.6 Inspection Finding of a Component in a Split Train Support System When the Failure of the Entire System is an Initiating Event and Could Impact the Mitigating System Capability Which Can Be Explicitly Determined

For inspection findings that involve the unavailability of a component in a split train support system when the failure of the whole system is a special initiator, increase the Initiating Event Likelihood (IEL) by one order of magnitude for the associated special initiator. In addition, determine the impact on the mitigation capability of the supported 
systems and evaluate each of the worksheets directed by Table 2, "Initiators and System Dependency," nominally for the affected supported systems.

Basis:

Simple reliability models and generic data have been used to estimate the failure probabilities of plant equipment. Failure of a component in a split train system where the total failure of the system is a special initiator is equivalent to a condition of a reduced redundancy. Therefore, an order of magnitude increase will be appropriate.

\section{Example:}

Consider an inspection finding that involves the unavailability of a normally standby pump in a service water system. The service water system is a split train support system with one pump running in each train and a standby pump that is automatically aligned upon failure of a running pump. The supported mitigating systems that are impacted, but not failed, by the increased unavailability of the service water system are one of two emergency diesel generators (EDGs) and one of two trains of the residual heat removal (RHR) system. Total failure of the service water system is a special initiator. The exposure time associated with this inspection finding is 21 days. The loss of service water special initiator is located in Row III of Table 1, "Categories of Initiating Events," for the affected plant. As a result, an IEL of 4 would normally be assigned when solving loss of service water accident sequences for this finding. But, because of the finding, an IEL of 3 would be used. In addition, each of the worksheets specified by Table 2, "Initiators and System Dependency," for the EDGs and the RHR system need to be solved nominally.

\section{A.2.1.7 Inspection Findings Involving Emergency Diesel Generators}

For inspection findings that involve the unavailability of emergency diesel generators (EDGs), determine the impact on mitigation capability of the supported systems and evaluate the loss of offsite power (LOOP) worksheet accounting for the unavailability of the EDG and the affected supported systems. In addition, if the LOOP with loss of one AC bus (LEAC) special initiator is modeled, then increase the Initiating Event Likelihood (IEL) by two orders of magnitude and evaluate the worksheet with the changed likelihood for LEAC.

Basis:

The unavailability of an EDG does not increase the likelihood of a LOOP event; therefore, the LOOP IEL is not adjusted when performing the LOOP worksheet. The frequency of LEAC is estimated by multiplying the frequency of a LOOP event with the unavailability of an EDG (approximately 1E-2). If the inspection finding is related to the unavailability of an EDG, then the frequency of LEAC should be the same as the frequency of a LOOP event. In addition, because most plants have two trains of emergency $A C$ power and many of the mitigating systems have more than two trains, the loading of the emergency AC 
buses is asymmetrical. Therefore, the LEAC worksheet reflects the loss of the emergency $\mathrm{AC}$ bus with the greatest risk impact.

\section{Example:}

Consider an inspection finding that involves the unavailability of one of two EDGs at a PWR. The supported mitigating systems that are impacted by the unavailability of one train emergency AC power includes one train of each of the auxiliary feedwater (AFW), high pressure safety injection (HPSI), and residual heat removal (RHR) systems. The exposure time associated with this inspection finding is 270 days. In accordance with Table 2, "Initiators and System Dependency," for the affected plant, the LOOP and LEAC worksheets need to be evaluated. The LOOP initiator is located in Row II of Table 1, "Categories of Initiating Events," for the affected plant. As a result, an IEL of 2 is assigned when solving LOOP accident sequences. The LEAC initiator is located in Row IV of Table 1, "Categories of Initiating Events." As a result, an IEL of 4 would normally be assigned when solving LEAC accident sequences; but, because the inspection finding increases the likelihood of a LEAC event, an IEL of 2 would be used. When solving the LOOP worksheet, the EDG and the equipment that it supports needs to be considered unavailable and the remaining mitigation capability modified accordingly. In this example, one train of each of the AFW, HPSI, and RHR systems is assumed unavailable in determining the remaining mitigation capability. In those sequences where $\mathrm{AC}$ power has been recovered (annotated as AC Recovered on the worksheets), full credit is given for the supported mitigating equipment because offsite power is available and the equipment does not need an EDG to perform its function. The LEAC worksheet already takes into account the equipment lost by the unavailability of the EDG; however, each sequence needs to be solved because the LEAC initiating event frequency is a contributor in each of these sequences.

\section{A.2.1.8 Inspection Findings Involving Safety-Related Battery Chargers}

Inspection findings that involve the unavailability of a battery charger for a safety-related DC bus should be treated as a potential loss of DC bus if there is no spare battery charger available and no recovery action can be taken. In addition, all other worksheets should be evaluated assuming the loss of the associated DC bus.

Inspection findings that involve the unavailability of a battery charger for a safety-related DC bus when a spare charger is available and/or recovery action can be taken should be treated by increasing the initiating event frequency for loss of the DC bus by one order of magnitude and evaluating the base case for all other worksheets.

If loss of DC bus is not a special initiator, then all the worksheets should be evaluated considering all equipment affected by loss of that $\mathrm{DC}$ bus. If the inspection finding is judged to be a potential loss of the DC bus (no spare charger), then the affected equipment is assumed unavailable. If the inspection finding is judged to increase the likelihood of the loss of the bus (there is at least one spare charger), then the worksheet is solved nominally. 
Basis:

Loading of a DC bus without an operable charger would result in eventual battery depletion and therefore the loss of the associated DC bus. Also, prolonged loss of a battery charger without any recovery action or alignment of an alternate charger could render the DC bus inoperable.

\section{Example:}

Consider an inspection finding that involves the unavailability of the battery charger for one of two safety-related DC buses and the facility does have an installed spare which is automatically aligned. The exposure time associated with this inspection finding is 1 day. The loss of DC bus special initiator is located in Row IV of Table 1, "Categories of Initiating Events," for the affected plant. As a result, an Initiating Event Likelihood (IEL) of 6 would normally be assigned when solving loss of DC bus accident sequences; but, because the inspection finding increases the likelihood of a loss of DC bus event, an IEL of 5 would be used. Each of the sequences on the loss of DC bus worksheet would then have to be solved because the loss of DC bus initiating event frequency is a contributor in each of these sequences.

Now consider an inspection finding that involves the unavailability of the battery charger for one of two safety-related DC buses and the facility does not have an installed spare. In this case, each of the worksheets specified by Table 2, "Initiators and System Dependency," for the equipment powered by the affected DC train need to be solved considering the associated DC bus is unavailable. This would typically involve most of the worksheets in the notebook.

\section{A.2.1.9 Inspection Findings Involving Safety-Related Battery}

Inspection findings that involve the unavailability of an emergency battery bank should be treated differently depending on the capacity of the associated battery charger in carrying the safety injection (SI) loads. If the battery chargers cannot carry the SI loads, the inspection finding that involves the unavailability of an emergency battery should be treated as the loss of the associated DC bus for all initiators specified in Table 2. If the battery chargers can carry the SI loads as footnoted in Table 2, the inspection finding that involves the unavailability of an emergency battery should be treated as the loss of the associated DC bus only in LOOP and LEAC worksheets. In addition, the loss of Battery bank would also necessitate increasing the Loss of DC frequency (if it is a special initiator) by one order of magnitude.

\section{Basis:}

In some plants the battery charger cannot carry the SI loads. Loss of the associated battery will therefore render the DC bus unavailable for all initiators when SI is actuated. Alternatively, when the charger is capable of carrying the SI loads, the DC bus will only 
be unavailable under Station Blackout (SBO) scenarios where there would be no AC power to the chargers.

\section{Example:}

Consider an inspection finding that involves the unavailability of the battery for one of two safety-related DC buses and the facility does not have battery chargers capable of carrying the SI loads. The exposure time associated with this inspection finding is 1 day. The loss of DC bus special initiator is located in Row IV of Table 1, "Categories of Initiating Events," for the affected plant. As a result, an Initiating Event Likelihood (IEL) of 6 would normally be assigned when solving loss of DC bus accident sequences; but, because the inspection finding increases the likelihood of a loss of DC bus event, an IEL of 5 would be used. Each of the sequences on the loss of DC bus worksheet would then be solved because the loss of DC bus initiating event frequency is a component in each of these sequences. In addition, each of the worksheets specified by Table 2, "Initiators and System Dependency," for the equipment powered by the affected DC train needs to be solved considering the associated DC bus is unavailable.

Now consider the case where the facility has battery chargers of sufficient capacity to carry the SI loads. The exposure time associated with this inspection finding is 1 day. The LOOP and LEAC initiators are in Rows II and IV respectively. For 1 day exposure time, the LOOP and LEAC will have an initiating event likelihood of 4 and 6 respectively. Since one of the emergency diesel generators (EDGs) cannot be started without the associated battery, the LEAC IEL should be raised by two orders of magnitude to an IEL of 4 . The LOOP worksheet therefore will be solved assuming an IEL of 4 and failure of one DC bus and the associated EDG. The LEAC worksheet will be solved nominally with an IEL of 4 . Similarly, the loss of DC bus special initiator is located in Row IV of Table 1, "Categories of Initiating Events," for the affected plant. As a result, an Initiating Event Likelihood (IEL) of 6 would normally be assigned when solving loss of DC bus accident sequences; but, because the inspection finding increases the likelihood of a loss of DC bus event, an IEL of 5 would be used.

\section{A.2.2 Determining Remaining Mitigation Capability}

A.2.2.1 Inspection Finding that Degrades Mitigation Capability But Does Not Reduce Remaining Mitigation Capability Credit to a Value Less Than Full Mitigation Credit

For inspection findings that involve the unavailability of mitigating system equipment, such that sufficient mitigation capability remains to receive full mitigation credit for the affected safety function, solve and count all of the worksheet sequences that contain the safety function giving full mitigation credit. 
Basis:

All of the worksheet sequences that contain the safety function are solved giving full mitigation credit because the increase in risk due to the degradation is less than one order of magnitude (i.e., it is assumed to be increased by a factor of 2).

\section{Example:}

Consider an inspection finding that involves the unavailability of one steam generator power-operated relief valve (SG PORV) on one of four steam generators. Each steam generator has one SG PORV and four safety relief valves. All worksheets specified in Table 2, "Initiators and System Dependency," would need to be evaluated considering one SG PORV unavailable. A review of the safety functions on each of these worksheets will reveal that the safety functions impacted by the inspection finding are secondary heat removal and rapid cooldown and depressurization. However, because all four steam relief valves are available on the affected steam generator, sufficient mitigation capability remains to receive full mitigation credit for these functions. Therefore, each sequence on these worksheets that contain these safety functions needs to be solved giving full mitigation credit for the function.

A.2.2.2 Inspection Finding (Normally Split Train Support System) that Does Not Increase the Likelihood of an Initiating Event and the Impact on Mitigating System Capability Can Be Explicitly Determined

For inspection findings that involve the unavailability of one train of a normally split train support system that does not increase the likelihood of an initiating event, determine the impact on the mitigation capability of the supported systems and evaluate each of the worksheets directed by Table 2, "Initiators and System Dependency," for the unavailability of the affected supported systems.

Basis:

Evaluation of this type of inspection finding involves a direct application of the SDP with the simultaneous unavailability of multiple systems.

\section{Example:}

Consider an inspection finding that involves the unavailability of one of two trains of an emergency service water (ESW) system. The ESW system is a standby, split train support system for the auxiliary feedwater system, the high pressure safety injection system, the residual heat removal system, and the emergency diesel generators. As a result, one of two trains of each of these systems is unavailable. In accordance with Table 2, "Initiators and System Dependency," all of the worksheets would need to be evaluated considering one train of each of these systems unavailable for the exposure time associated with the finding. 


\section{A.2.2.3 Inspection Findings Involving a Loss of Redundancy of Equipment}

When an inspection finding reduces the remaining mitigation capability such that the total available equipment is less than two times the equipment that is required to fulfill the safety function, the remaining mitigation capability credit should not exceed one train.

Basis:

The SDP worksheets typically assume that if the mitigation capability is such that a single failure can be tolerated without loss of a function, then multi-train credit is assigned. However, if an inspection finding indicates that a performance issue contributed to the failure of at least one train of a system, there is a higher potential for a common cause failure mechanism. In such cases single train credit is more appropriate when the remaining mitigation capability does not provide full redundancy (twice the number of trains required).

Example:

Consider a finding that involves the unavailability of one train of a low pressure injection system. The system is normally a four train system that requires two trains to satisfy the success criteria (e.g., 2/4 trains [multi-train system]). Each of the worksheets specified by Table 2, "Initiators and System Dependency," for this system needs to be solved considering one train unavailable. When solving each of the worksheets that credit this system, only one train of remaining mitigation capability credit would be given because of the loss of redundancy (e.g., 2/3 trains [1 train]) in this system.

\section{A.2.2.4 Inspection Findings Involving Equipment that Impact Operator Action Credit}

When evaluating inspection findings that impact safety functions involving mitigating equipment and operator action, the remaining mitigation credit should correspond to the equipment or operator action credit, whichever is most limiting.

Basis:

The failure of safety functions that are composed of both equipment and operator action can occur by the failure of either the equipment or the operator action. Because the associated failure probabilities are relatively small, the failure probability of the safety function can be determined by adding the individual failure probabilities together. Consequently, the failure probability of the safety function can be approximated by the order of magnitude of the most limiting component. For example, a safety function is comprised of a multi-train system which has a failure probability of 1E-3 coupled with an operator action which has a failure probability of $1 \mathrm{E}-2$. Therefore, the failure probability of the safety function is $1.1 \mathrm{E}-2$, or approximately $1 \mathrm{E}-2$. 


\section{Example:}

Consider an inspection finding involving the failure of one of the high pressure safety injection (HPSI) pumps. One of the safety functions impacted by this finding is high pressure recirculation (HPR). The success criteria for the HPR function is one of two HPSI pumps, one of two residual heat removal (RHR) pumps and one of two RHR heat exchangers with operator action for switchover (operator action credit $=3$ ). With one HPSI pump unavailable, the remaining mitigation capability becomes equipment limited and a credit of 2 (1 train) should be assigned to the HPR function.

\section{A.2.3 Characterizing the Risk Significance of Inspection Findings}

\section{A.2.3.1 Treatment of Shared Systems Between Units}

When evaluating inspection findings that involve systems that impact multiple units, the inspection finding should be evaluated for each unit separately.

Basis:

The risk significance of an inspection finding is attributed to the unit on which it is applicable. If the inspection finding affects more than one unit and it affects the units differently, then the SDP should be conducted once for each unit as it applies to that unit.

\section{Example:}

Consider an inspection finding that involves the unavailability of an emergency diesel generator (EDG). The particular EDG is credited as mitigating equipment on the dedicated unit and a second unit via an operator action to crosstie the EDG. Therefore, the inspection finding needs to be evaluated separately for each unit. For the dedicated unit, the finding would be evaluated as a finding involving a normally standby, split train support system that increases the likelihood of an initiating event and the impact on mitigating system capability can explicitly be determined. For the other unit, the inspection finding would be evaluated as a finding that impacts the remaining mitigation capability, the ability to crosstie the EDG, which is credited in certain accident sequences. Specifically, only LOOP and LEAC accident sequences that contain the emergency $\mathrm{AC}$ power function need to be solved. As a result, the inspection finding will result in separate risk characterizations for each unit which may be different.

\section{A.2.3.2 Counting Rule}

Every three affected accident sequences that have the same order of magnitude of risk, as determined by the addition of the initiating event likelihood and the remaining mitigation capability, constitute one equivalent sequence which is more risk significant by one order of magnitude. This rule is applied in a cascading fashion. 
Basis:

The Counting Rule is necessary because the risk significance of an inspection finding is determined by the increase in core damage frequency due to the associated performance deficiency. This risk increase represents the summation of the changes in risk associated with each of the affected accident sequences. A simplified rule was needed to relate accident sequences that represent different orders of magnitude of risk significance. Judgment and experience with the use of the Phase 2 Notebooks were utilized in the establishment of this rule.

Examples:

Consider an inspection finding that affects three accident sequences in the Phase 2 Notebook that each have a risk significance of 7 , which is Green. Using the Counting Rule, these three accident sequences would constitute an equivalent accident sequence one order of magnitude more risk significant, which is 6 or White.

Now consider an inspection finding that affects a total of eight accident sequences in the Phase 2 Notebook. One sequence has a risk significance of 7, Green, and seven sequences have a risk significance of 8 . Using the Counting Rule, the seven sequences of 8 would constitute two equivalent 7 sequences. In turn, these two sequences when added with the 7 sequence would equate to one sequence of 6 or White. 
APPENDIX B

\section{OPERATOR ACTION CREDIT FOR SDP NOTEBOOKS}




\section{LIST OF TABLES}

Table

Page

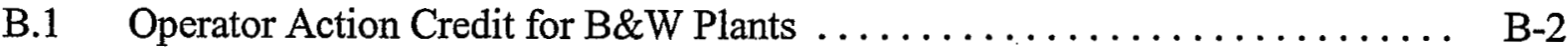

B.2 Operator Action Credit for CE Plants $\ldots \ldots \ldots \ldots \ldots \ldots \ldots \ldots \ldots \ldots$ B-3

B.3 Operator Action Credit for 2-Loop Westinghouse Plants $\ldots \ldots \ldots \ldots \ldots$ B-4

B.4 Operator Action Credit for 3-Loop Westinghouse Plants $\ldots \ldots \ldots \ldots \ldots$ B-5

B.5 Operator Action Credit for 4-Loop Westinghouse Plants $\ldots \ldots \ldots \ldots \ldots$ B-6

B.6 Operator Action Credit for General Electric BWR Plants . . . . . . . . . . . . . B-7 
In the notebooks, operator actions are considered for applicable mitigation features and an attempt is made to treat similar operator actions consistently to avoid variations in assessment of risk significance of inspection findings due to variability in human reliability analysis of operator actions. Credits for operator actions are defined based on a survey of human error probabilities (HEPs) of the action across plants of similar design. HEPs of an operator action is collected from the plant-specific PRAs and a geometric mean* of the HEPs for the action considering plants of similar design is obtained. This geometric mean is used to define the operator action credit. An operator action credit of 1 represents a HEP in the range of 5E-2 to less than 5E-1, an operator action credit of 2 represents a HEP in the range of 5E-3 to less than 5E-2, and an operator action credit of 3 represents a HEP in the range of 5E-4 to less than 5E-3. In some select cases, when the operator action is considered highly reliable, an operator action credit of 4 may be assigned. In this appendix, we present the operator action credits for the actions across plants of a specific design. These credits were defined based on the survey of the HEPs discussed above.

${ }^{*}$ Geometric mean of $x_{1}, x_{2}, \ldots, x_{n}=\sqrt[n]{x_{1} \cdot x_{2} \cdot \ldots \cdot x_{n}}$ 
Table B.1 Operator Action Credit for B\&W Plants

\begin{tabular}{|l|c|c|}
\hline \multicolumn{1}{|c|}{ Operator Action } & $\begin{array}{c}\text { HEP } \\
\text { (Geometric Mean) }\end{array}$ & Operator Action Credit \\
\hline $\begin{array}{l}\text { Conduct feed and bleed operation } \\
\text { (maintain HPI cooling) }\end{array}$ & 0.0082 & 3 \\
\hline $\begin{array}{l}\text { Initiate high pressure recirculation } \\
\text { (HPR) }\end{array}$ & 0.0006 & 3 \\
\hline $\begin{array}{l}\text { Initiate low pressure recirculation } \\
\text { (LPR) in MLOCA }\end{array}$ & 0.0025 & 2 \\
\hline $\begin{array}{l}\text { Initiate low pressure recirculation } \\
\text { (LPR) in LLOCA }\end{array}$ & 0.0091 & 3 \\
\hline Isolate the faulted Steam Generator & 0.0039 & $3^{(1)}$ \\
\hline $\begin{array}{l}\text { Equalize and depressurize in a steam } \\
\text { generator tube rupture (SGTR) }\end{array}$ & 0.00014 & $3^{(1)}$ \\
\hline $\begin{array}{l}\text { Initiate shutdown cooling (SDC) in } \\
\text { a SGTR }\end{array}$ & 0.000086 & 2 \\
\hline $\begin{array}{l}\text { Initiate borated water storage tank } \\
\text { (BWST) makeup in a SGTR }\end{array}$ & 0.014 & 2 \\
\hline $\begin{array}{l}\text { Initiate emergency boration in an } \\
\text { anticipated transient without scram } \\
\text { (ATWS) }\end{array}$ & 0.007 & $2^{(2)}$ \\
\hline Throttle HPI flow in MSLB & 0.0039 & 3 \\
\hline Trip the RCPs & & 2 \\
\hline Align alternate AC sources & 0022 & 2 \\
\hline Close block valve & & 2 \\
\hline
\end{tabular}

Notes:

1. A credit of 3 is assigned since in the SDP notebook approach a credit higher than 3 is assigned in exceptional cases.

2. No data was available for $B \& W$ plants for this action. A credit of 2 is assigned based on judgment. 
Table B.2 Operator Action Credit for CE Plants

\begin{tabular}{|l|c|c|}
\hline \multicolumn{1}{|c|}{ Operator Action } & $\begin{array}{c}\text { HEP } \\
\text { (Geometric Mean) }\end{array}$ & Operator Action Credit \\
\hline $\begin{array}{l}\text { Control main feedwater (MFW) } \\
\text { pumps }\end{array}$ & 0.0041 & 3 \\
\hline Conduct feed and bleed operation & 0.012 & 2 \\
\hline $\begin{array}{l}\text { Align alternate auxiliary feedwater } \\
\text { (AFW) }\end{array}$ & 0.0056 & $3^{(1)}$ \\
\hline $\begin{array}{l}\text { Initiate condensate storage tank } \\
\text { (CST) makeup }\end{array}$ & 0.00042 & 3 \\
\hline Close block valve & 0.00126 & 3 \\
\hline Isolate the faulted SG & 0.00325 & 3 \\
\hline $\begin{array}{l}\text { Equalize and depressurize in a steam } \\
\text { generator tube rupture (SGTR) }\end{array}$ & 0.000826 & $2^{(2)}$ \\
\hline $\begin{array}{l}\text { Initiate reactor coolant system } \\
\text { (RCS) depressurization }\end{array}$ & 0.047 & $1^{(2)}$ \\
\hline $\begin{array}{l}\text { Initiate rapid depressurization of the } \\
\text { RCS }\end{array}$ & 0.27 & 2 \\
\hline Initiate shutdown cooling (SDC) & 0.0077 & 3 \\
\hline Trip reactor coolant pump (RCP) & 0.0015 & $4^{(3)}$ \\
\hline Align Alternate AC & 0.016 & 2 \\
\hline $\begin{array}{l}\text { Initiate switchover from cold leg to } \\
\text { hot leg recirculation }\end{array}$ & 0.00022 & 2 \\
\hline
\end{tabular}

Notes:

1. A credit of 3 is assigned since in the SDP notebook approach a credit higher than 3 is assigned in exceptional cases.

2. Data in theses cases are based on one plant.

3. An exception is made for this action (a credit of 4) considering the time available and the relative ease of the action. 
Table B.3 Operator Action Credit for 2-Loop Westinghouse Plants

\begin{tabular}{|l|c|c|}
\hline \multicolumn{1}{|c|}{ Operator Action } & $\begin{array}{c}\text { HEP } \\
\text { (Geometric Mean) }\end{array}$ & Operator Action Credit \\
\hline $\begin{array}{l}\text { Restart main feedwater (MFW) in a } \\
\text { transient }\end{array}$ & 0.0025 & 3 \\
\hline Initiate feed and bleed & 0.014 & 2 \\
\hline $\begin{array}{l}\text { Initiate high pressure recirculation } \\
\text { (HPR) }\end{array}$ & 0.012 & 2 \\
\hline Restart MFW in a SLOCA/SGTR & 0.015 & 3 \\
\hline $\begin{array}{l}\text { Initiate reactor coolant system } \\
\text { (RCS) depressurization }\end{array}$ & 0.0015 & 2 \\
\hline Initiate rapid RCS depressurization & 0.039 & 2 \\
\hline $\begin{array}{l}\text { Initiate low pressure recirculation } \\
\text { (LPR) }\end{array}$ & 0.011 & 3 \\
\hline Close the block valve & 0.0013 & 2 \\
\hline Isolate the ruptured SG & 0.008 & 2 \\
\hline $\begin{array}{l}\text { Equalize and depressurize in a } \\
\text { SGTR }\end{array}$ & 0.01 & 2 \\
\hline $\begin{array}{l}\text { Initiate shutdown cooling (SDC) in } \\
\text { a SGTR }\end{array}$ & 0.024 & 2 \\
\hline $\begin{array}{l}\text { Refill refueling water storage tank } \\
\text { (RWST) }\end{array}$ & 0.013 & 2 \\
\hline Initiate emergency boration & 0.031 & 2 \\
\hline Trip reactor coolant pump (RCP) & 0.0019 & 2 \\
\hline Start charging pump & & 2 \\
\hline
\end{tabular}


Table B.4 Operator Action Credit for 3-Loop Westinghouse Plants

\begin{tabular}{|l|c|c|}
\hline \multicolumn{1}{|c|}{ Operator Action } & $\begin{array}{c}\text { HEP } \\
\text { (Geometric Mean) }\end{array}$ & Operator Action Credit \\
\hline $\begin{array}{l}\text { Restart main feedwater (MFW) in a } \\
\text { transient or SLOCA }\end{array}$ & 0.0022 & 3 \\
\hline Initiate feed and bleed & 0.033 & 3 \\
\hline $\begin{array}{l}\text { Initiate high pressure recirculation } \\
\text { (HPR) }\end{array}$ & 0.0024 & 3 \\
\hline $\begin{array}{l}\text { Initiate reactor coolant system } \\
\text { (RCS) depressurization }\end{array}$ & 0.0015 & 2 \\
\hline Initiate rapid RCS depressurization & 0.03 & 2 \\
\hline $\begin{array}{l}\text { Initiate low pressure recirculation } \\
\text { (LPR) in LLOCA }\end{array}$ & 0.038 & 3 \\
\hline Close the block valve & 0.0013 & 2 \\
\hline $\begin{array}{l}\text { Equalize and depressurize in a steam } \\
\text { generator tube rupture (SGTR) }\end{array}$ & 0.0057 & 3 \\
\hline $\begin{array}{l}\text { Initiate shutdown cooling (SDC) in } \\
\text { a SGTR }\end{array}$ & 0.0017 & 2 \\
\hline $\begin{array}{l}\text { Refill refueling water storage tank } \\
\text { (RWST) }\end{array}$ & 0.0053 & 3 \\
\hline Initiate emergency boration & 0.006 & 2 \\
\hline Trip reactor coolant pump (RCP) & 0.0011 & 2 \\
\hline
\end{tabular}


Table B.5 Operator Action Credit for 4-Loop Westinghouse Plants

\begin{tabular}{|l|c|c|}
\hline \multicolumn{1}{|c|}{ Operator Action } & $\begin{array}{c}\text { HEP } \\
\text { (Geometric Mean) }\end{array}$ & Operator Action Credit \\
\hline $\begin{array}{l}\text { Restart main feedwater (MFW) in a } \\
\text { transient }\end{array}$ & 0.016 & 2 \\
\hline Initiate feed and bleed & 0.021 & 2 \\
\hline $\begin{array}{l}\text { Initiate high pressure recirculation } \\
\text { (HPR) }\end{array}$ & 0.0016 & 3 \\
\hline Restart MFW in a SLOCA & 0.011 & 3 \\
\hline $\begin{array}{l}\text { Initiate reactor coolant system } \\
\text { (RCS) depressurization }\end{array}$ & 0.0021 & 2 \\
\hline Initiate rapid RCS depressurization & 0.017 & 3 \\
\hline $\begin{array}{l}\text { Initiate low pressure recirculation } \\
\text { (LPR) in SLOCA }\end{array}$ & 0.0015 & 3 \\
\hline Initiate LPR in a LLOCA & 0.0045 & 3 \\
\hline Close the block valve & 0.004 & 3 \\
\hline Isolate the ruptured SG & 0.002 & 2 \\
\hline $\begin{array}{l}\text { Equalize and depressurize in a steam } \\
\text { generator (SGTR) }\end{array}$ & 0.015 & 3 \\
\hline $\begin{array}{l}\text { Initiate residual heat removal (RHR) } \\
\text { in a SGTR }\end{array}$ & 0.0026 & 2 \\
\hline $\begin{array}{l}\text { Refill refueling water storage tank } \\
\text { (RWST) }\end{array}$ & 0.0036 & 2 \\
\hline Initiate emergency boration & 0.0058 & 2 \\
\hline Trip reactor coolant pump (RCP) & & 2 \\
\hline
\end{tabular}


Table B.6 Operator Action Credit for General Electric BWR Plants

\begin{tabular}{|l|c|c|}
\hline \multicolumn{1}{|c|}{ Operator Action } & $\begin{array}{c}\text { HEP } \\
\text { (Geometric Mean) }\end{array}$ & Operator Action Credit \\
\hline Restart main feed pumps/PCS & 0.0021 & 3 \\
\hline $\begin{array}{l}\text { Initiate depressurization in transients } \\
\text { and SLOCA }\end{array}$ & 0.0007 & 3 \\
\hline Initiate depressurization in MLOCA & 0.0021 & 2 \\
\hline Initiate depressurization in ATWS & 0.008 & $4^{(1)}$ \\
\hline Initiate suppression pool cooling & 0.00014 & 2 \\
\hline $\begin{array}{l}\text { Initiate containment venting } \\
\text { (controlled venting) }\end{array}$ & 0.015 & 2 \\
\hline $\begin{array}{l}\text { Initiate containment venting (not } \\
\text { throttled nor controlled) }\end{array}$ & 0.0014 & 2 \\
\hline $\begin{array}{l}\text { Initiate late injection using control } \\
\text { rod drive (CRD) }\end{array}$ & 0.0063 & 2 \\
\hline $\begin{array}{l}\text { Initiate late injection using fire } \\
\text { pumps }\end{array}$ & 0.012 & $2^{(3)}$ \\
\hline $\begin{array}{l}\text { Initiate late injection using high } \\
\text { pressure service water (HPSW) } \\
\text { pumps }\end{array}$ & 0.082 & 2 \\
\hline $\begin{array}{l}\text { Initiate late injection using } \\
\text { condensate pumps }\end{array}$ & 0.009 & 2 \\
\hline $\begin{array}{l}\text { Initiate late injection in harsh } \\
\text { environment }\end{array}$ & 0.0031 & 2 \\
\hline $\begin{array}{l}\text { Initiate standby liquid control (SLC) } \\
\text { in ATWS }\end{array}$ & & 2 \\
\hline $\begin{array}{l}\text { Inhibit automatic depressurization } \\
\text { system (ADS) in ATWS }\end{array}$ & & 2 \\
\hline Control overfill in ATWS & & 2 \\
\hline
\end{tabular}

\section{Notes:}

1. This operator action credit is kept at 4 considering the time available and the routine nature of this action.

2. Data for this action is based on one plant.

3. This action relates to using $2 / 2$ SLC pumps and the available time is more than 5 minutes. 